\title{
Targeting KRAS Mutant Non-Small-Cell Lung Cancer: Past, Present and Future
}

\author{
Iris Z. Uras ${ }^{1, *(\mathbb{C})}$, Herwig P. Moll ${ }^{2}(\mathbb{D})$ and Emilio Casanova 2,3 \\ 1 Department of Pharmacology, Center of Physiology and Pharmacology \& Comprehensive Cancer \\ Center (CCC), Medical University of Vienna, 1090 Vienna, Austria \\ 2 Department of Physiology, Center of Physiology and Pharmacology \& Comprehensive Cancer Center (CCC), \\ Medical University of Vienna, 1090 Vienna, Austria; herwig.moll@meduniwien.ac.at (H.P.M.); \\ emilio.casanova@meduniwien.ac.at (E.C.) \\ 3 Ludwig Boltzmann Institute for Cancer Research (LBI-CR), 1090 Vienna, Austria \\ * Correspondence: iris.urasjodl@meduniwien.ac.at
}

Received: 13 May 2020; Accepted: 11 June 2020; Published: 17 June 2020

\begin{abstract}
Lung cancer is the most frequent cancer with an aggressive clinical course and high mortality rates. Most cases are diagnosed at advanced stages when treatment options are limited and the efficacy of chemotherapy is poor. The disease has a complex and heterogeneous background with non-small-cell lung cancer (NSCLC) accounting for $85 \%$ of patients and lung adenocarcinoma being the most common histological subtype. Almost $30 \%$ of adenocarcinomas of the lung are driven by an activating Kirsten rat sarcoma viral oncogene homolog (KRAS) mutation. The ability to inhibit the oncogenic KRAS has been the holy grail of cancer research and the search for inhibitors is immensely ongoing as KRAS-mutated tumors are among the most aggressive and refractory to treatment. Therapeutic strategies tailored for KRAS ${ }^{+}$NSCLC rely on the blockage of KRAS functional output, cellular dependencies, metabolic features, KRAS membrane associations, direct targeting of KRAS and immunotherapy. In this review, we provide an update on the most recent advances in anti-KRAS therapy for lung tumors with mechanistic insights into biological diversity and potential clinical implications.
\end{abstract}

Keywords: lung adenocarcinoma; NSCLC; KRAS; targeted therapy; immunotherapy; metabolic rewiring; p53; STK11; EGFR; degraders

\section{Introduction}

Lung cancer remains the leading cause of cancer-related lethality worldwide, with nearly 1.6 million deaths, and the five-year survival rate is still below $20 \%$ [1]. Outcomes with platinum-based chemotherapy as first-line treatment in patients with stage IV non-small-cell lung cancer (NSCLC) are poor, with a clear need for improved treatments and for individualized therapeutic approaches for each patient [2-4]. NSCLC molecular profiling is a key factor in therapy decision making, with a number of emerging oncogenic targets and active targeted agents. Somatic mutations in epidermal growth factor receptor (EGFR) and rearrangements in anaplastic lymphoma receptor tyrosine kinase (ALK), proto-oncogene tyrosine-protein kinase ROS (ROS) and RET proto-oncogene (RET) have been nominated as solid predictive biomarkers and attractive drug targets in NSCLC $[5,6]$. The rat sarcoma proto-oncogene (RAS) family, the most frequently mutated oncogene family in cancer, however, has been defined as undruggable [7] and, despite four decades of efforts, no potent anti-RAS therapy is currently used in routine clinical practice.

The RAS gene family members encode a membrane-bound small GTPase and switch between the active guanosine triphosphate (GTP)-bound and inactive guanosine diphosphate (GDP)-bound state [8] 
(Figure 1). The activation of RAS signaling is tightly controlled by the regulator factors that promote the GDP-GTP exchange (guanine nucleotide exchange factors; GEFs) or affect its GTPase activity (GTPase-activating proteins; GAPs). GEFs and GAPs bind to one or both of the binding pockets on RAS (known as switch I and switch II regions) $[9,10]$. This process links upstream cell surface receptors such as EGFR, fibroblast growth factor receptor (FGFR) and human epidermal growth factor receptors 2-4 (HER2-4/ERBB2-4) to downstream pathways (e.g., rat fibrosarcoma/mitogen-activated protein kinase kinase/extracellular regulated kinase (RAF/MEK/ERK), phosphoinositide 3-kinase/protein kinase $\mathrm{B} /$ mechanistic target of rapamycin kinase (PI3K/AKT/mTOR) and Ral guanine nucleotide dissociation stimulator (RALGDS-RA)) promoting cell proliferation, differentiation or cell death [11-16] (Figure 2). Oncogenic mutations in RAS proteins impair their ability for GTP hydrolysis, resulting in the accumulation of GTP-bound active RAS (Figure 1) and hyperactivation of downstream signaling cascades that lead to uncontrolled cell proliferation and survival.

The three RAS family members that have been extensively evaluated in humans are Kirsten rat sarcoma viral oncogene homolog (KRAS), neuroblastoma rat sarcoma viral oncogene homolog (NRAS) and Harvey rat sarcoma viral oncogene homolog (HRAS). The frequency and distribution of RAS mutations are not uniform. KRAS is the isoform most frequently altered in $86 \%$ of RAS mutant cancer cases, followed by NRAS $11 \%$ and HRAS 3\% [17]. KRAS aberrations are mainly found in lung, pancreatic and colon cancer, NRAS in melanoma and HRAS in bladder and head and neck squamous cancers [18]. KRAS mutations account for approximately 30\% of lung adenocarcinomas in Western countries and for 10-15\% of cases in Asia [19]. The $K R A S^{G 12 C}$ mutation is highly prevalent in patients suffering from lung adenocarcinoma (13\% of total lung adenocarcinoma) and account for $>50 \%$ of all KRAS mutant cases [20].

Although KRAS was one of the earliest oncogenic drivers discovered, effective KRAS-targeted therapies still remain elusive. KRAS mutant lung cancers have worse outcomes in both early stage and advanced metastatic settings, illustrating the critical need for novel agents targeting KRAS-driven NSCLC. Numerous therapeutic strategies have been developed including targeting KRAS membrane associations, synthetic lethality partners, blockage of downstream signaling cascades, targeting metabolic reprogramming, direct targeting of KRAS and immunotherapy (Figure 3). In this review, we provide a critical assessment of past efforts and discuss the most promising improvements for future success.

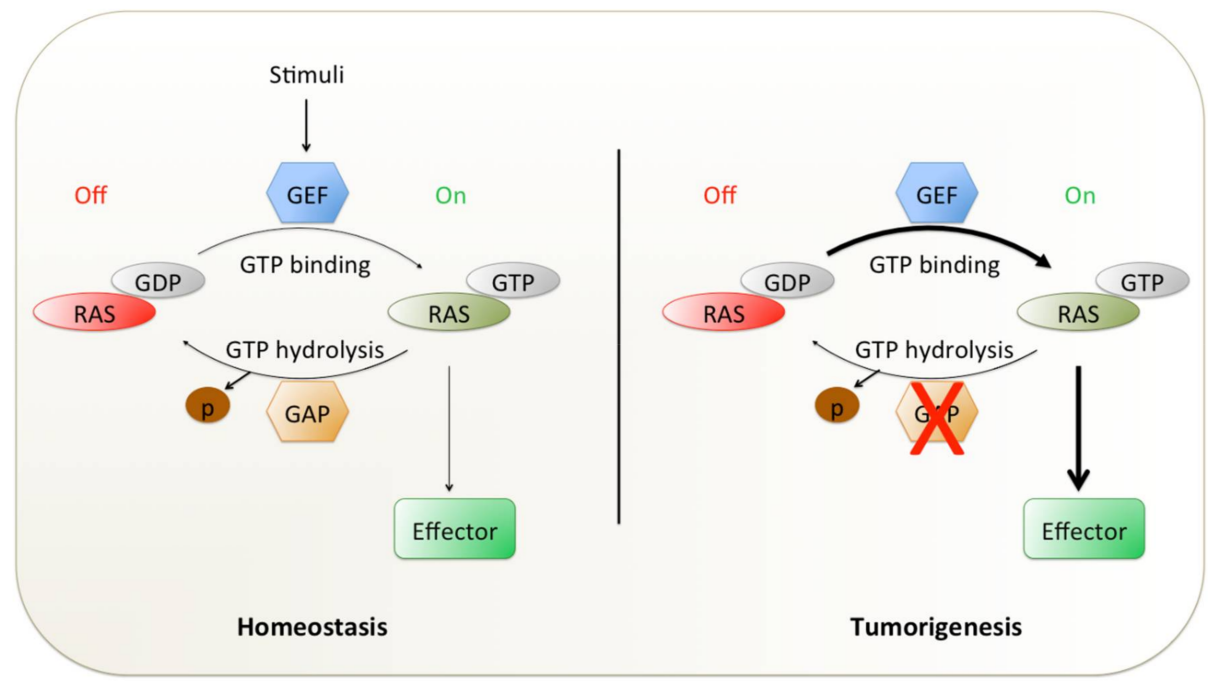

Figure 1. The two states of RAS family GTPases. GTP- and GDP-bound states are directed by GEFs and GAPs. GEFs stimulate the exchange of GDP to GTP, promoting activation of RAS (On). GAPs drive GTP hydrolysis and return to inactive GDP-bound status (Off). The thickness of the arrows indicates the strength of GTP binding as well as the (hyper)activation of downstream effectors. The red cross indicates the impairment of GTP hydrolysis. GEF: guanine nucleotide exchange factor; GAP: GTPase-activating protein; GTP: guanosine triphosphate; GDP: guanosine diphosphate; RAS: rat sarcoma proto-oncogene 


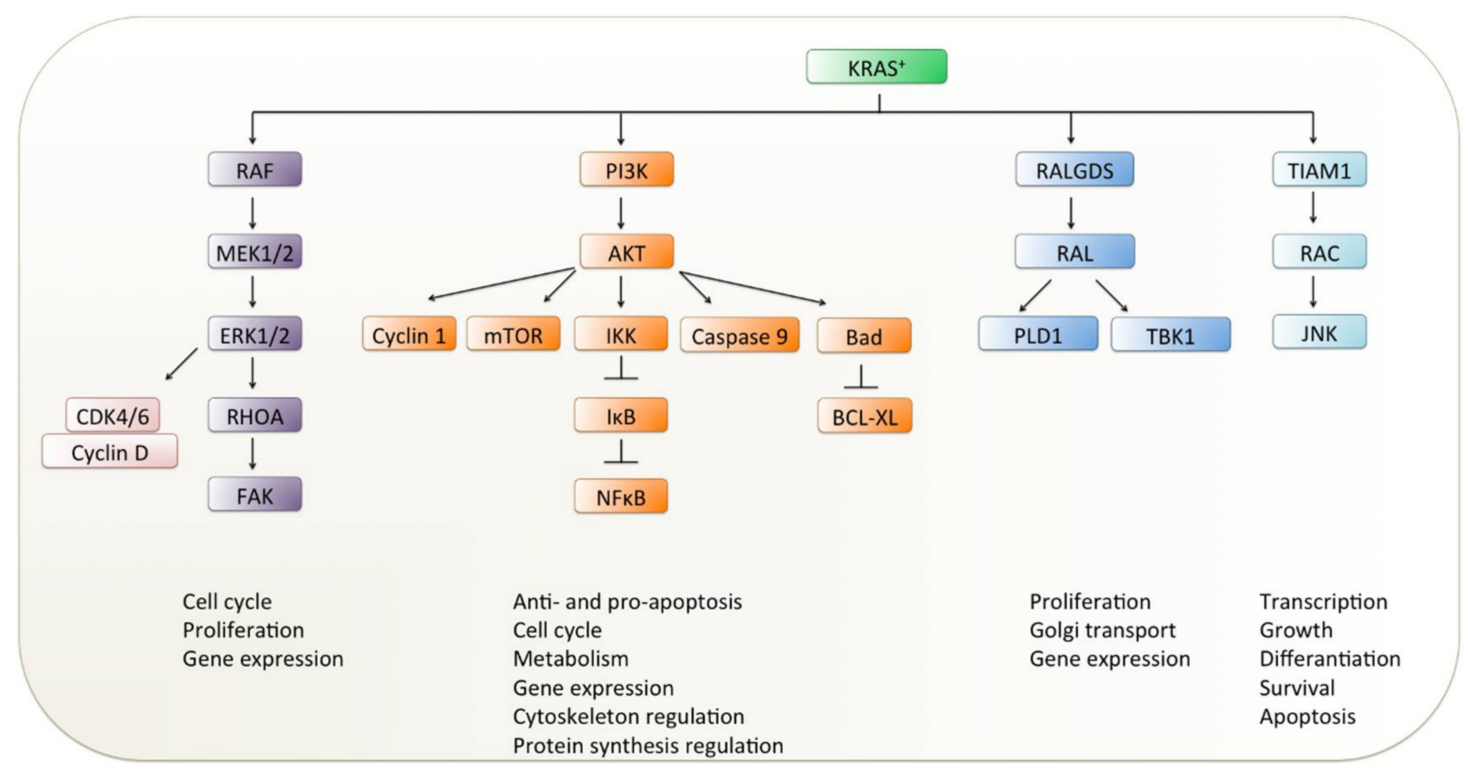

Figure 2. KRAS signaling in non-small-cell lung cancer (NSCLC). Schematic presentation of signaling pathways initiated by oncogenic KRAS aberrations is illustrated in a simplified fashion. RAF: rat fibrosarcoma; MEK: mitogen-activated protein kinase kinase; ERK: extracellular regulated kinase; PI3K: phosphoinositide 3-kinase; AKT: protein kinase B; mTOR: mechanistic target of rapamycin kinase; RALGDS: Ral guanine nucleotide dissociation stimulator; KRAS: Kirsten rat sarcoma viral oncogene homolog; CDK4/6: cyclin-dependent kinase 4/6; RHOA: Ras homolog family member; FAK: focal adhesion kinase; IKK: IkappaB kinase; IкB: nuclear factor of kappa light polypeptide gene enhancer in B-cells inhibitor; NF-kB: nuclear factor 'kappa-light-chain-enhancer' of activated B-cells; Bad: BCL2-associated agonist of cell death; BCL-XL: B-cell lymphoma-extra large; RAL: Ras-like protein; PLD1: phospholipase D1; TBK1: TANK binding kinase 1; TIAM1: T lymphoma invasion and metastasis-inducing protein 1; RAC: Ras-related C3 botulinum toxin substrate 1; JNK: c-Jun $\mathrm{N}$-terminal kinase. 


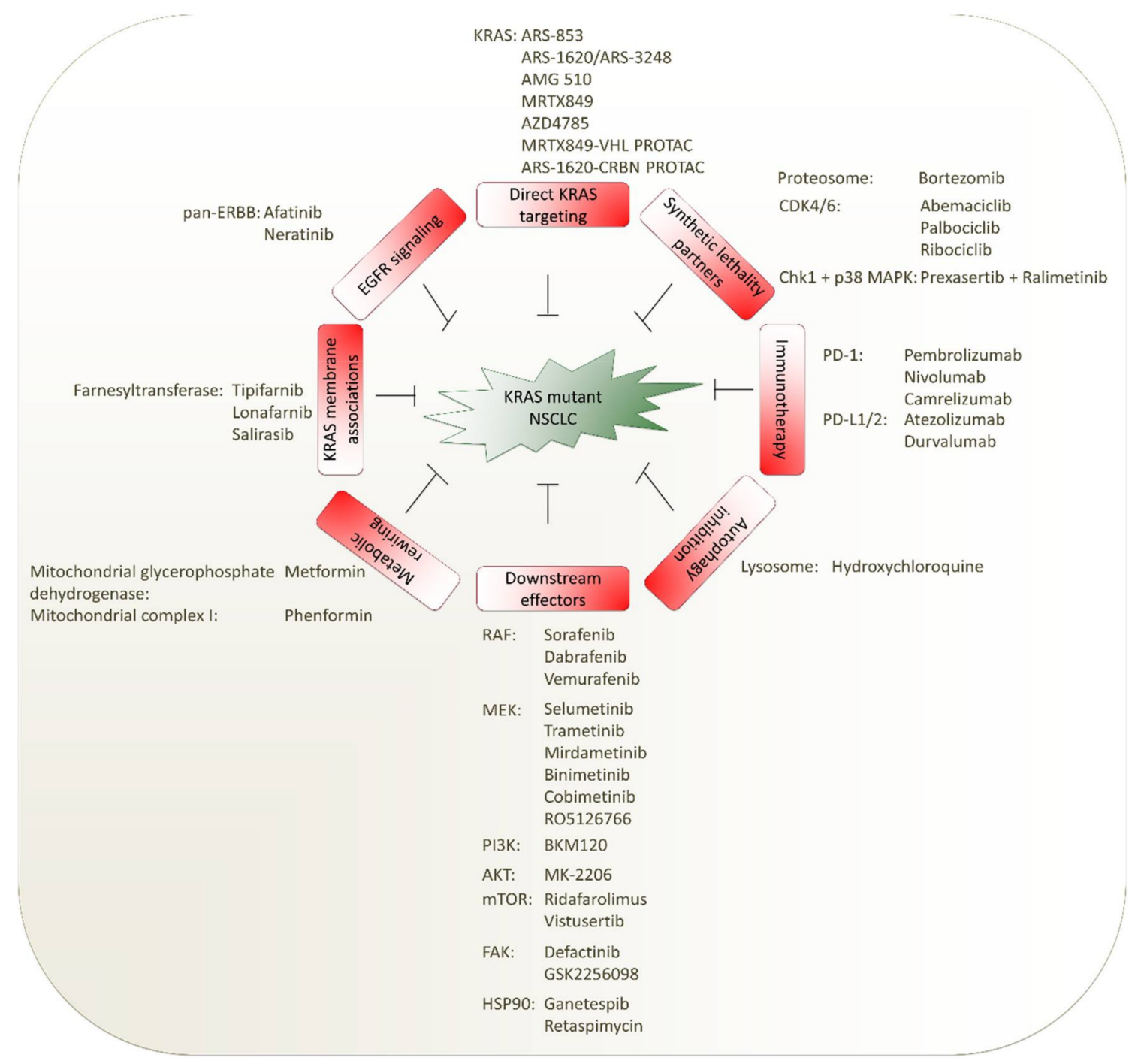

Figure 3. Therapeutic approaches to tackle KRAS mutant NSCLC in patients. Selected compounds and their targets are listed. CDK4/6: cyclin-dependent kinase 4/6; Chk1: checkpoint kinase 1; CRBN: cereblon; PROTAC: proteolysis-targeting chimeras; VHL: von Hippel-Lindau disease tumor suppressor; HSP90: heat shock protein 90; RAF: rat fibrosarcoma; MEK: mitogen-activated protein kinase kinase; PI3K: phosphoinositide 3-kinase; AKT: protein kinase B; mTOR: mechanistic target of rapamycin kinase; KRAS: Kirsten rat sarcoma viral oncogene homolog; FAK: focal adhesion kinase; ERBB: human epidermal growth factor receptor; PD-1: programmed cell death protein 1; PD-L: programmed cell death 1 ligand; MAPK: mitogen-activated protein kinase.

\section{Molecular Diversity in KRAS Mutant NSCLC Influences Effective Targeting}

KRAS-mutated NSCLC is composed of a heterogeneous set of distinct diseases. Co-occurring genetic events, distinct $K R A S$ mutation subtypes, and mutant $K R A S$ allelic content are among the main drivers that contribute to direct clinical implications.

KRAS mutant NSCLC often appears with additional genetic alterations-a feature not shared by other oncogene-driven NSCLC. Recent RNA sequencing efforts in KRAS ${ }^{+}$NSCLC defined three expression clusters dominated by the co-mutations in serine/threonine kinase 11 (STK11, also known as liver kinase B1 (LKB1)) and tumor protein $p 53$ ( $p 53$ ), inactivation of cyclin-dependent kinase inhibitor $2 A / B(C D K N 2 A / B)$ and low levels of thyroid transcription factor-1 [21]. KRAS/STK11 driven tumors were characterized by hypoxia-inducible factor-1 alpha-mediated metabolic reprogramming and adaptation to oxidative and endoplasmic reticulum stress and showed enrichment in Kelch-like ECH-associated protein 1 
(KEAP1) mutations ${ }^{21}$. KRAS/CDKN2A/B-mediated tumors were enriched in gene expression signatures of gastrointestinal neoplastic processes and wildtype p53 transcriptional activity [21]. The presence of major co-mutations is of prognostic significance (e.g., STK11 or KEAP1 mutations are associated with worse overall survival) and of predictive value for therapeutic vulnerabilities [21-23].

Mutational subtype of individual KRAS mutations is of greater relevance than the categorical evaluation of its presence or absence. To date, the most frequent KRAS mutations in NSCLC have been documented at codons 12 and 13 [24]. Among those, glycine 12 to cysteine (G12C) and glycine 12 to valine $(\mathrm{G} 12 \mathrm{~V})$ are the most common subtypes associated with a smoking history, whereas glycine 12 to aspartic acid (G12D) is mainly found in never smokers [24-26]. Each amino acid substitution differs in its binding affinity for downstream effectors: KRAS ${ }^{\mathrm{G} 12 \mathrm{D}}$ had higher affinity for PI3K/AKT signaling, whereas KRAS ${ }^{G 12 C}$ or KRAS ${ }^{G 12 V}$ led to low levels of phosphorylated AKT and increased RAL activation compared with other mutations or wildtype situation [27]. Two independent studies in metastatic patients and in those with surgically resected NSCLC are in favor with the idea that different codon variants may promote activation of distinct transcriptional networks which impact on prognosis and/or therapeutic susceptibilities: KRAS ${ }^{G 12 C}$ or KRAS ${ }^{G 12 V}$ positivity was associated with worse disease-free and overall survival when compared with other KRAS variants or wildtype protein, at least partly due to increased levels of epithelial to mesenchymal transition genes and lower levels of genes predicting KRAS dependency [28,29]. However, reports in adjuvant and advanced settings failed to prove any prognostic significance based on $K R A S$ mutational subtype $[21,30,31]$.

A common feature among KRAS mutant NSCLC is the metabolic rewiring of tumors towards anabolism [32]. Not only does the presence of certain co-mutations define distinct metabolic and redox management profiles [21], but also the mutant KRAS allelic content is a major contributor [33]. $K R A S^{G 12 D / G 12 D}$ cells exhibited a glycolytic switch towards glutathione biosynthesis and a higher metastatic potential. These changes were recapitulated in spontaneous advanced murine lung tumors with a high frequency of KRAS ${ }^{G 12 D}$ copy gain (homozygous) but not in the corresponding early tumors (KRAS ${ }^{G 12 D}$ heterozygous). Tumors with KRAS ${ }^{G 12 D}$ allelic enrichment had lower survival rates than heterozygous tumors and were highly susceptible to the glycolytic inhibitor 2-deoxyglucose and the glutathione synthesis inhibitor buthionine sulfoximine. These data suggest that KRAS mutant NSCLC may be classified on a metabolic basis for a better therapeutic outcome.

Taken together, one common feature of earlier studies without succeeding to improve outcome upon treatments was that detailed information on the genetic context of individual tumors was unobtainable in the vast majority of patients [34]. Hence, future efforts of anti-RAS therapy in NSCLC should be stratified based on the primary drivers of its biological diversity.

\section{Treatment Failures of the Past in Mutant KRAS NSCLC}

For almost four decades, a therapeutic breakthrough in targeting KRAS has been hampered by structural and biochemical obstacles, prompting the widely held perception that RAS proteins are untargetable. Several factors contribute to these obstacles: (i) KRAS binds to GTP with picomolar affinity in its active state and this interaction needs more potent inhibition than that granted by traditional blockers; and (ii) clear druggable pockets on KRAS large enough for small-molecule binding were/are missing [7,34]. Therefore, tackling of mutant KRAS has been focused on inhibition of its membrane association/subcellular localization, identification of synthetic lethality partners, and inhibition of downstream effectors. Yet neither strategy has yielded significant successes for many years.

\subsection{Blocking KRAS Membrane Association}

RAS proteins require membrane associations for their biological activation, making this association a logical target for anti-RAS drug development. Once synthesized in the cytosol, they become lipophilic for membrane attachment. Lipid alteration of RAS proteins by the linkage of 15-carbon farnesyl polyisoprene onto the cysteine of C-terminal CAAX motifs is an obligate step in this process catalyzed 
by the farnesyltransferase (prenylation) [35]. Farnesyltransferase inhibitors (FTIs) represent the most well-known example of treatment failure in targeting mutant $R A S$. The first-generation drugs tipifarnib and lonafarnib were well tolerated but with poor clinical efficacy in advanced NSCLC [36,37]. Such lack of activity was thought to be due to the alternative prenylation of RAS by geranylgeranyltransferase I (GGTase I) [38,39]: the geranylgeranylation of KRAS still permits its membrane localization and signal transduction, overcoming the effect of FTI. However, dual inhibition of farnesyltransferase and geranylgeranyltransferase did not yield any clinical benefit [40]. The second-generation FTI salirasib, at the dose and schedule applied in a phase II trial, exhibited insufficient activity in the treatment of KRAS mutant lung adenocarcinoma [41] despite the promising preclinical data [42,43]. Such lack of efficacy might be due to alternative resistance mechanisms (e.g., KRAS gene amplification) or off-target effects and demands a better understanding. Of note, considering RAS mutant isoforms in these settings has proven essential for designing and delivering trials: contrary to KRAS and NRAS, HRAS protein does not undergo alternative prenylation and application of FTIs to HRAS mutant cell lines has been effective [39].

Targeting of enzymes involved in post-prenylation of RAS such as RAS-converting enzyme 1 (RCE1) and isoprenyl carboxyl methyltransferase (ICMT1) renewed interest in efforts for anti-RAS therapeutics. Although Rce1 or Icmt1 deficiency in mouse embryonic fibroblasts impaired HRAS-mediated transformation, later studies provided puzzling results about loss of these enzymes: (i) absence of Rce1 in mouse hematopoietic cells accelerated $K R A S^{G 12 D}$-driven myeloproliferative disease [44], whereas inactivation of Icmt 1 in the same mouse model had a protective effect; [45] (ii) Icmt1 deficiency in the pancreas enhanced KRAS ${ }^{G 12 D}$-driven neoplastic progression [46]. These discrepancies might be explained by the fact that both enzymes have up to 300 additional substrates that may be differentially sensitive to enzyme blockage in a context-dependent manner. Several RCE1 and ICMT1 inhibitors have been developed and characterized [47-49] but further optimization is needed before their entrance in human trials.

Other enzymatically regulated modifications involved in RAS trafficking, subcellular localization and/or effector interactions that are promising directions to achieve the goal of disrupting RAS include de-/palmitoylation, phosphorylation, endothelial nitric oxide synthase-catalyzed nitrosylation, ubiquitination and acetylation. However, developing potent and selective inhibitors might be challenging due to a wide spectrum of substrates. The precise biological mechanisms driving KRAS membrane association, the enzymology of such modifications, the significance of their stoichiometry and their potential therapeutic value should be fully characterized before entering clinical testing $[7,35]$.

\subsection{Synthetic Lethality Partners as Therapeutic Vulnerabilities}

One alternative indirect approach to attack KRAS function in cancer has been to seek targets that are essential in cells bearing activated KRAS oncogene but not those without. This so-called synthetic lethal approach in cancer treatment, rooted in ideas from invertebrate genetics [50,51], has been inspired most strongly by the use of poly(ADP-ribose)polymerase (PARP) inhibitors in the clinic to treat breast cancer gene (BRCA)-negative tumors [52,53].

Several drug library screens or cell line-based genetic screens using RNA interference (RNAi)-mediated expression silencing or clustered regularly interspaced short palindromic repeats/CRISPR-associated protein 9 (CRISPR/Cas9) technology have been carried out to identify genes that are uniquely essential to KRAS mutant but not wildtype cells. Their results can be categorized into the following cellular processes: cell cycle and mitosis (survivin, targeting protein for Xklp2 (TPX2), polo-like kinase 1 (PLK1), anaphase-promoting complex/cyclosome (APC/C), cell survival (Wilms tumor 1 (WT1), B-cell lymphoma-extra large (BCL-XL1), transcriptional programs (GATA-binding protein 2 (GATA2), snail family transcriptional repressor 2 (SNAIL2) and growth and survival signals (TANK binding kinase 1 (TBK1), mitogen-activated protein kinase kinase kinase 7 (MAP3K7/TAK1) [7]. The findings of KRAS dependency on kinases (e.g., TBK1 [54]) and transcription factors (e.g., GATA2 $[55,56])$ suggest the involvement of additional cellular pathways to support 
the viability of KRAS transformed cells. Unfortunately, these large-scale screens suffer from various limitations including high genetic complexity of KRAS mutant cells (large number of activating co-occurring alterations), experimental artefacts (e.g., choice of cell line, inconsistency of methodology), low magnitude of synthetic lethality effect and lack of validation $[57,58]$. The problematic can be exemplified as follows: (i) after its identification as a synthetic lethal partner using an RNAi screen in KRAS mutant cell lines [59], inhibition of STK33's kinase activity by the small molecule BRD-8899 proved ineffective [60]; (ii) although three independent groups defined GATA2 as essential for survival of KRAS mutant NSCLC [55,56,61], Tessema et al. showed that GATA2 is epigenetically repressed in human and mouse lung tumors and its inhibition is not a valid therapeutic strategy for KRAS mutant lung cancer [62]. In fact, the screens have been notable for little or no target overlap between their results, with the exception of proteosome-related genes [58]. Bortezomib, a proteosome inhibitor, was associated with modest anti-tumor activity and durable disease control in a small fraction of patients with $K R A S^{\mathrm{G} 12 \mathrm{D}}$ mutant lung tumors [63,64]. However, KRAS ${ }^{\mathrm{G} 12 \mathrm{D}}$ mutation alone is not a robust predictor of response and further evaluation should only be performed after elucidation of co-mutations and histologic subtype that may predict therapy sensitivity [63,64]. It is also likely that significant response would be achieved when combined with other agents. Apart from chemotherapeutics, a possible combination partner could be MEK inhibition, currently the only targeted therapy with selectivity for KRAS mutations in the clinic (approved for $B-R A F^{V 600 E}$-mutated NSCLC). In fact, the essentiality of MEK signaling to RAS-mediated transformation has led to a combinatorial synthetic lethality screen with MEK inhibitors, which has revealed the anti-apoptotic BH3 family gene BCL-XL as a potential sensitivity hit [65].

Another interesting synthetic lethal strategy describes combined inhibition of discoidin domain receptor 1 (DDR1) and NOTCH signaling [66]. The tyrosine kinase receptor DDR1 was identified as the top-scoring gene in transcriptional profiling of $K R A S^{G 12 V}$-driven mouse hyperplasias. The concomitant blockage of DDR1 and NOTCH signaling induced regression of KRAS/p53 co-mutated patient-derived xenografts (PDX) with a therapeutic efficacy greater than standard chemotherapy.

A further potential therapeutic application in NSCLC has been unveiled by recent mouse work: genetic and chemical blockage of cyclin-dependent kinase 4 (CDK4) was synthetic lethal in genetically modified KRAS-driven lung tumor models [67]. Consistently, a multi-tumor phase I trial reported that the CDK inhibitor abemaciclib (Verzenios, Lily; with greater selectivity to CDK4 than its close homolog CDK6) achieved a higher disease control rate in NSCLC patients with KRAS mutations than without [68]. However, in a phase III trial comparing abemaciclib vs. erlotinib (an EGFR inhibitor) as second- or third-line treatment of advanced KRAS mutant NSCLC (NCT0215631), overall survival (the primary endpoint) did not differ between the two study arms [69]. Palbociclib (Ibrance, Pfizer), another U.S. Food and Drug Administration (FDA)-approved CDK4/6 inhibitor, is in clinical evaluation for KRAS mutant NSCLC either in combination with MEK inhibitors (NCT02022982, NCT03170206) or with the glutaminase inhibitor telaglenastat (CB-839) (NCT03965845). Another trial is underway to assess the preliminary efficacy of the CDK4/6 inhibitor ribociclib (Kisqali, Novartis) in combination with protein tyrosine phosphatase non-receptor type 11 (PTPN11) inhibitor TNO155 (NCT04000529). Further cell cycle-related proteins have been described as synthetic lethal partners of KRAS signaling in vitro and in vivo: mitotic catastrophe was observed in KRAS-mutated but not wildtype tumors when exposed to inhibitors of checkpoint kinase 1 (Chk1) and MAPK-activated protein kinase 2 (MK2) [70]. A phase I trial (NCT02860780) has been conducted to evaluate the combination of prexasertib (a Chk1 inhibitor) and ralimetinib (a p38 MAPK inhibitor) in patients with advanced or metastatic cancer including NSCLC with results being not available as yet.

Despite recent advances, to date, KRAS synthetic lethality has fallen short of its original promise and remains unproven as routine clinical practice to attack KRAS ${ }^{+}$NSCLC. 


\subsection{Targeting Downstream Effectors of KRAS Signaling}

Many of the downstream effectors of the KRAS pathway (e.g., RAF, MEK, PI3K and mTOR) are rational therapeutic targets and their potential value has been evaluated in many NSCLC clinical trials. Different $K R A S$ codon subtypes show a preference for activating different downstream signaling [27]; hyperactivation of the MAPK pathway is a key feature in KRAS-driven lung cancer. One explanation for this is that the most common subtype G12C exhibits more prominent engagement with MAPK signaling [71]. Several clinical trials are underway evaluating the potential of the inhibition of KRAS functional output by single agents or in combinatorial schedules with chemotherapy, other targeted agents and/or radiation therapy (e.g., NCT03415126, NCT01859026, NCT02964689, NCT03704688, NCT01306045, NCT01912625, NCT02185690, NCT04121286, NCT03990077, NCT02450656, NCT03989115, NCT04045496).

\subsubsection{RAF Inhibitors}

The direct RAS downstream effectors within the RAF/MEK/ERK pathway are the RAF kinases $\mathrm{v}$-Raf murine sarcoma 3611 viral oncogene homolog 1 (A-), v-Raf murine sarcoma viral oncogene homolog B (B-) and v-Raf-1 murine leukemia viral oncogene-like protein 1 (C-RAF). One of the first drugs aimed at blocking KRAS/RAF/MEK/ERK signaling was sorafenib [72]. The multikinase inhibitor sorafenib exerts modest activity against RAF kinases yet efficacy in patients with KRAS mutant lung tumors is rather disappointing with an increase of 3 months in median progression-free survival (PFS) [73-76]. Further, KRAS mutational status was not of any predictive value in the BATTLE and MISSION trials when sorafenib was administered as a single agent in relapsed/refractory NSCLC patients $[73,75,76]$.

Dabrafenib and vemurafenib, both type I B-RAF inhibitors, are potent in targeting $B-R A F$ mutant NSCLC but show no benefit in patients with KRAS mutations. This is explained by the fact that C-RAF but not B-RAF plays a unique role in mediating KRAS oncogenic signaling. Ablation of $C-R A F$ recapitulated the effects of disrupting KRAS and completely blocked tumor initiation without any significant toxicities observed in KRAS-driven lung tumor mouse models [77,78]. In advanced tumors driven by $K R A S^{G 12 V} / p 53$, systemic abrogation of C-RAF expression induced regression due to massive apoptosis by a mechanism independent of canonical MAPK signaling which is also essential for normal homeostasis $^{79}$. The observed therapeutic benefit was likely due to the disrupted interaction between C-RAF protein and other partners (e.g., B-cell lymphoma 2 (BCL2), apoptosis signal-regulating kinase 1 (ASK1), serine/threonine kinase 3 (STK3), and Rho-associated coiled-coil containing protein kinase 2 (ROCK2)) [79]. This might explain, at least partly why $C-R A F$ absence did not induce any significant adverse events, in contrast to MEK inhibitors. The catalytic activity of C-RAF is not required for the KRAS-mediated transformation [79]: three C-RAF inhibitors (MLN2480, GW5074, and PLX8394) designed to block the kinase activity but not the protein expression failed to yield any therapeutic effect [71,79]. Opposing the currently ongoing efforts to generate C-RAF kinase inhibitors, these studies rather encourage the development and implication of C-RAF specific degraders [72,80].

\subsubsection{MEK Inhibitors}

Genetic studies have helped to dissect the requirements for each member of the MAPK pathway in KRAS induced tumors. Individual MEK1/2 kinases are dispensable for the initiation of lung adenocarcinomas driven by $K R A S^{G 12 V}$, whereas complete elimination of MEK expression efficiently prevents tumor development [77]. Several MEK inhibitors have been developed-most of which are allosteric kinase inhibitors. They are highly specific and less likely to cause off-target toxicity due to their affinity for a unique allosteric pocket on MEK, rather than for the catalytic site with its higher homology to other kinases [81]. However, MEK inhibition is notably susceptible to adaptive feedback via reactivation of MAPK signaling [82].

A phase II trial failed to show improvement in objective response rate (ORR) or PFS upon concomitant combination therapy of selumetinib (an allosteric MEK inhibitor) and erlotinib (an 
anti-EGFR inhibitor) over monotherapy in KRAS mutant and KRAS wildtype advanced NSCLC [83]. The ORR in the KRAS mutant arm was $0 \%$ for selumetinib alone and $10 \%$ for the combination. Combination therapy resulted in increased toxicities, requiring dose reductions and discontinuation. Programmed cell death 1 (PD-1) expression on regulatory T cells (Tregs), $\mathrm{T}$ cell immunoglobulin mucin-3 (Tim-3) on CD8 ${ }^{+} \mathrm{T}$ cells and T helper 17 (Th17) levels were associated with PFS and overall survival in patients receiving selumetinib [83]. Further, in an unselected NSCLC population, there was no suggestion that selumetinib monotherapy demonstrates superiority with standard second-line pemetrexed-based chemotherapy [84]. In a randomized phase II trial, concomitant treatment with selumetinib plus docetaxel (a taxane chemotherapy) suggested an incremental survival advantage but with higher numbers of adverse events than with docetaxel alone in previously treated KRAS mutant NSCLC [85]. However, these results could not be recapitulated in the larger phase III SELECT-1 trial (NCT01933932) [86]. Such lack of therapeutic response might be caused by the impact of co-existing genetic modifiers. In a preclinical study using mouse models, simultaneous loss of either $p 53$ or STK11, both clinically relevant tumor suppressors, markedly impaired the response of KRAS mutant tumors to docetaxel alone [87]. The addition of selumetinib offered substantial benefit for mice bearing KRAS and KRAS/p53 mutations, whereas KRAS/STK11 mutant mice displayed primary resistant to the therapy due to activation of parallel signaling pathways such as AKT and v-Src avian sarcoma (Schmidt-Ruppin A-2) viral oncogene homolog (SRC) [87]. In addition, the impact of specific KRAS codon subtypes warrants further investigation in future clinical trials.

Trametinib is another selective and potent MEK inhibitor that has been clinically approved for $B-R A F$ mutations, mainly to treat melanoma [81]. However, the drug showed similar PFS and a response rate as docetaxel in patients with previously treated KRAS-mutated NSCLC [88]. Activation of compensatory proteins/pathways may offer insight into why these clinical disappointments have occurred. A phase II trial with KRAS-driven NSCLC reported a trend for worse PFS in G12C cohorts compared to non-G12C patients (NCT02642042) [89].

\subsubsection{Other Downstream Inhibitors}

KRAS oncogenic signaling also involves PI3K/AKT/mTOR via the interaction with the catalytic subunits of PI3K. Inhibiting RAS-driven PI3K activation blocks the progression of KRAS ${ }^{+}$tumors [90-92]. However, the mTOR inhibitor ridaforolimus as monotherapy displayed little clinical benefit in a phase II trial in KRAS mutant NSCLC resulting only in a modest increase in PFS [93]. Various phase I trials have been investigating the efficacy of targeting PI3K/AKT/mTOR pathway in combination with MEK inhibitors in patients with advanced-stage solid tumors including NSCLC [94-96]. Preliminary evidence of partial responses was reported in patients with solid tumors but not specifically in those with NSCLC. One potential obstacle for clinical approval of this approach might be that drug dosages for a complete abrogation of RAS signaling through PI3K/mTOR and MEK inhibition could be too high to be tolerated in humans [57].

The non-receptor tyrosine kinase focal adhesion kinase (FAK) involved in cell adhesion to the extracellular matrix is critical for cancer cell proliferation, survival, migration, and invasion and has also been explored as a target. The KRAS/RHOA/FAK pathway plays an important role in the development of lung tumors bearing inactivated $p 53$ or loss of CDKN2A [97]. A phase II trial of the FAK inhibitor defactinib failed to improve outcome in patients with KRAS mutant lung tumors [98] (NCT01951690). One reason behind might be co-occurring genetic events: FAK inhibitors have been documented to exert potent anti-tumor activity in NSCLC with KRAS ${ }^{G 12 V}$ mutation in association with CDKN2A deficiency but not in CDKN2A wildtype background [97]. A phase Ib dose-finding, pharmacokinetic trial has been initiated to determine the maximum tolerated dose of the FAK inhibitor GSK2256098 and the MEK1/2 inhibitor trametinib in combination in eligible patients having mesothelioma or other solid tumors with MAPK activation [99]. Equivalent effect between GSK2256098 plus trametinib combination and those from an earlier GSK2256098 monotherapy study was observed in regard of 
reduction in FAK levels. The clinical efficacy of the combination was limited although safety profiles were acceptable up to the maximum tolerated dose.

The use of heat shock protein 90 (HSP90) inhibitors in KRAS mutant NSCLC also appeared to be a promising approach as these molecules target many KRAS downstream effectors. The HSP90 inhibitor AUY922 attenuated intrinsic resistance to PI3K and MEK inhibitors by suppressing both PI3K/AKT/mTOR and RAF/MEK/ERK signaling in KRAS mutant NSCLC cells [100,101]. Panaxynol is a natural HSP90 inhibitor and disrupts its function by binding to its $\mathrm{N}$-terminal and C-terminal ATP-binding pockets. The compound inhibited the sphere forming ability of NSCLC cancer stem-like cells (CSCs) and suppressed the viability of NSCLC cells (non-CSCs) and their sublines with acquired chemoresistance, whereas normal cells derived from various organs were not affected [102]. Upon oral administration, panaxynol blocked lung tumorigenesis in KRAS ${ }^{G 12 D /+}$ transgenic mice and mice carrying NSCLC xenografts without detectable toxicity. However, the clinical efficacy of HSP90 inhibitors is limited due to rapid resistance. In addition, in a phase III lung cancer trial of ganetespib (a HSP90 inhibitor) and docetaxel (an anti-microtubule agent), the combination failed to demonstrate any benefits. Hyperactivation of RAF/MEK/ERK/RSK and PI3K/AKT/mTOR pathways was defined as a key resistance mechanism to ganetespib [103]. Activity of p90 ribosomal S6 kinase (p90RSK; a key activator of the mTOR pathway and an ERK downstream target) was increased in KRAS mutant NSCLC ganetespib resistant cells. While genetic or pharmacologic inhibition of p90RSK restored sensitivity to ganetespib, reactivation of p90RSK and its downstream target M-phase inducer phosphatase 3 (CDC25C) promoted bypass of the ganetespib induced $\mathrm{G}_{2} / \mathrm{M}$ arrest and led to acquired resistance to ganetespib and cross-resistance to docetaxel in KRAS mutant NSCLC [103,104]. Simultaneous application of ganetespib and p90RSK or CDC25C inhibitors was highly synergistic, suggesting that the development of rationally designed HSP90 inhibitor combinations may prevent or overcome resistance to HSP90 inhibition [104].

\section{New Optimism for Targeting KRAS Mutations}

Advanced technologies in drug development and novel mechanistic insights into KRAS biology paved the way to refocus attention on strategies that directly interfere with the function of KRAS oncoproteins, with a particular interest in how to attack specific mutant alleles.

\subsection{Covalent KRAS Inhibitors vs. KRAS Protein Degradation}

One of the reasons for conducting indirect inhibition of KRAS was that in vivo blockage of the catalytic site with nucleotide competitive inhibitors is not feasible, at least in part due to the high affinity of RAS for GTP/GDP together with their high intracellular concentrations [105]. Recent advances have identified two classes of cysteine 12-modifying KRAS inhibitors which either bind to the nucleotide pocket of KRAS [106] or to the neighboring switch II region [107]. ARS-853, a potent G12C allele-specific inhibitor, reduced KRAS signaling and cancer cell growth in vitro $[108,109]$. These studies further illustrated that mutant RAS is not locked in a GTP-RAS constitutively active state: KRAS ${ }^{\mathrm{G} 12 \mathrm{C}}$ alteration enhances rapid nucleotide exchange (GDP-GTP) and thus leads to aberrant downstream signaling. This suggests that KRAS allelic substitutions are still sensitive to extracellular growth factors and their activity could be tackled by blocking upstream effectors. ARS- 853 inactivated KRAS ${ }^{\mathrm{G} 12 \mathrm{C}}$ signaling by a trapping mechanism: KRAS ${ }^{\mathrm{G} 12 \mathrm{C}}$ was trapped in the GDP-RAS state, hindering further nucleotide exchange $[108,109]$. Concomitant treatment of ARS-853 with other tyrosine kinase inhibitors (TKIs) (e.g., EGFR TKI) or monoclonal antibodies blocking other receptor tyrosine kinases (RTKs) upstream of RAS showed synergistic activity [108,109]. Hence, complete blockage of RAS signaling may require combinatorial strategies with these compounds. However, ARS-853 has not entered clinical evaluations in KRAS mutant lung cancer as yet.

Optimization of the cysteine conjugation and the molecular interactions within the drug-induced pocket has led to the development of oral KRAS ${ }^{\mathrm{G} 12 \mathrm{C}}$ inhibitors: ARS-1620/ARS-3248 (Wellspring Biosciences), AMG 510 (Amgen/Carmot Therapeutics) and MRTX849 (Mirati Therapeutics) induced 
regression of KRAS ${ }^{G 12 C}$ tumors [110-112]; the latter three entered phase I clinical trials (NCT04006301, NCT03600883, NCT03785249, NCT04303780, NCT04330664) [113]. Unfortunately, initial high hopes have been dampened by rapid adaptive resistance and MAPK signaling reactivation following inhibitor treatment $[114,115]$.

Different from the covalent inhibitors that specifically target mutant KRAS, AZD4785 is a KRAS antisense-oligonucleotide (ASO) targeting KRAS gene irrespective of its mutational status [116]. AZD4785 potently depleted KRAS mRNA and protein, inhibited downstream effector pathways and led to anti-proliferative effects in mutant KRAS cells. Unlike observations with RAS/MAPK pathway inhibitors, ASO-driven depletion of KRAS was not associated with feedback activation of MAPK cascade. Anti-tumor activity was confirmed in mice harboring KRAS-mutated NSCLC xenografts and patient-derived xenografts. Despite the safety reports obtained in mice and monkeys, the first phase I trial in NSCLC and advanced solid tumors failed (NCT03101839). The underlying reason might be that AZD4785 does not distinguish between mutant and wildtype KRAS for degradation.

New optimism has been sparked by proteolysis-targeting chimeras (PROTACs) [80] targeting KRAS ${ }^{\mathrm{G} 12 \mathrm{C}}$ mutants. These bifunctional molecules simultaneously engage $\mathrm{KRAS}^{\mathrm{G} 12 \mathrm{C}}$ protein and an E3 ligase, forming a ternary complex, enabling the E3 ligase to ubiquitinate KRAS ${ }^{\mathrm{G} 12 \mathrm{C}}$ protein on proximal lysine residues. Zeng et al. has reported a cysteine 12-directed covalent degrader molecule incorporating ARS-1620 and thalidomide to recruit the cereblon E3 ligase which degraded an artificial GFP-KRAS ${ }^{\mathrm{G} 12 \mathrm{C}}$ fusion protein in reporter cells but not endogenous KRAS ${ }^{\mathrm{G} 12 \mathrm{C}}$ in pancreatic and lung cancer cells [117]. Recently, Bond et al. described the first endogenous KRAS ${ }^{\mathrm{G} 12 \mathrm{C}}$ degrader [118]. Docking of cysteine 12-directed covalent inhibitor MRTX849 into the switch II pocket of KRAS G12C revealed the pyrrolidine group to be solvent exposed; the linkers were extended directly from the pyrrolidine ring nitrogen. LC-2 was identified as the most potent KRAS ${ }^{\mathrm{G} 12 \mathrm{C}}$ degrading PROTAC, incorporating MRTX849 and the VHL E3 ligase ligand, which resulted in rapid engagement and sustained degradation. KRAS ${ }^{\mathrm{G} 12 \mathrm{C}}$ degradation by LC-2 depended on both proteasome and neddylation (neddylation of cullin 2, a VHL adaptor protein, is required for assembly and function of the VHL E3 ligase complex [119]) as pretreatment with epoxomicin or MLN4924, respectively, rescued KRASG12C levels. On the other hand, bafilomycin A1, an inhibitor of lysosomal acidification, proved ineffective indicating that LC-2-mediated KRAS ${ }^{\mathrm{G} 12 \mathrm{C}}$ degradation requires ternary complex formation with VHL and an intact ubiquitin proteasome system, whereas the lysosomal pathway is dispensable. Upon exposure to LC-2, phosphorylated ERK (pERK) signaling was attenuated for up to $72 \mathrm{~h}$ in multiple cancer cell lines including NSCLC cells. Total ERK was elevated in cells treated with the degrader molecule compared to vehicle controls at all time points indicating the initiation of a positive feedback loop upon KRAS ${ }^{G 12 C}$ degradation and pERK inhibition. As the covalent nature of LC-2 may limit its potency (because it cannot participate in multiple catalytic rounds of degradation), reversible degrader molecules attacking KRAS are needed. Ligand development for other KRAS mutations is ongoing. Although in vivo studies are awaited, the discovery of LC-2 is a milestone in anti-KRAS ${ }^{\mathrm{G} 12 \mathrm{C}}$ cancer therapy.

\subsection{Improved Combinatorial Downstream Strategies for KRAS Mutant Lung Tumors}

The clinical failure of agents against the RAF/MEK/ERK pathway downstream of RAS in KRAS mutant cancers has led to explore the possibility of using combinations of targeted agents inhibiting the multiple pathways downstream of RAS. Such a dual strategy provides the additional value of attacking two main downstream pathways and resulted in encouraging signals of activity in preclinical and in early phase trials.

Preclinical studies have suggested combinations of mTOR and MEK inhibitors in KRAS mutant lung cancers [120] but these attempts have proven challenging due to adverse events such as diarrhea, skin rash and fatigue [121]. Broutin et al. investigated the dependence of MEK and mTOR inhibition in a panel of KRAS mutant and KRAS wildtype NSCLC cell lines and showed for the first time that inhibition of mTOR but not MEK contributes to the majority of the growth inhibition in this 
combination [122]. There was no significant additive difference in growth inhibition caused by mTOR compared with mTOR plus MEK inhibition in KRAS wildtype cells, whereas the combination caused a significantly greater growth inhibition than either compound alone in KRAS-mutated cells. The results further suggest that in terms of toxicity, clinical trial designs using intermittent dosing should prioritize reducing the dose/frequency of the MEK inhibitor rather than mTOR inhibitor. Furthermore, Liang et al. recently reported that combinations of clinically approved MTOR inhibitors and chemotherapeutics synergized in inhibiting cell proliferation of KRAS mutant NSCLC cells in vitro and in vivo, and the efficacy of this approach correlated with the magnitude of mTOR activity induced by chemotherapy alone [123].

An open-label, phase Ib clinical trial has been initiated to determine the maximum tolerated dose and/or the recommended dose for use in a phase II trial for BKM120 (an oral PI3K inhibitor) in combination with binimetinib (an FDA-approved allosteric MEK inhibitor) (NCT01363232). This combination has been explored in patients with EGFR mutant pretreated NSCLC, triple-negative breast cancer, pancreatic cancer, colorectal cancer, malignant melanoma, NSCLC and other advanced solid tumors with KRAS, NRAS and/or B-RAF mutations; the results are not available yet. Another doseand schedule-finding study evaluated MK-2206 (an allosteric inhibitor of pan-AKT) and selumetinib in patients with advanced treatment-refractory solid tumors (NCT01021748) [124]. Clinical anti-tumor activity was observed with durable tumor shrinkage in KRAS-mediated NSCLC and low-grade ovarian carcinoma. Strikingly, no responses were documented in KRAS-mutated colorectal or small-bowel carcinoma, partly due to distinct biological context differences in these diseases. Such heterogeneity of response among patients with $K R A S^{+}$tumors mirrors the complexities of tumor biology and the presence of other aberrant driver mutations or disruption of signaling feedback loops.

A recent study reported that MEK/bromodomain and extraterminal domain (BET) inhibitors suppress pre-replication complex proteins in cycling cells and trigger stalled replication, DNA damage and death [125]. This combination is effective in half of KRAS-mutated NSCLC and cause potent tumor regression in xenograft and PDX models. Another potential combinatorial downstream strategy for KRAS-mutated lung tumors employed a short hairpin RNA screen [126]. Manchado et al. reported that the MEK inhibitor trametinib provokes a compensatory response via FGFR-1-mediated adaptive resistance in KRAS mutant lung cancer cells. As a consequence, genetic or chemical blockage of FGFR-1 (with ponatinib) together with trametinib enhances cell death in $K R A S^{G 12 V}$ positive tumors in vitro and in vivo. Recently, Molina-Arcas et al. described a promising combinatorial strategy using mTOR, insulin-like growth factor 1 receptor (IGF1R) and MEK inhibitors to treat lung tumors bearing KRAS allelic substitutions [127]. Marked tumor regression was achieved in various mouse models. While each component of this triple drug combination has been found to cause adverse events in clinical trials, substitution of MEK inhibitor with the recently developed allele-specific KRASG12C inhibitor ARS-1620 allowed strong inhibition of KRAS ${ }^{G 12 C}$ positive tumors with low toxicity and markedly boosted the effects of ARS-1620 monotherapy. This study provides insights into how best to use KRAS $^{\mathrm{G} 12 \mathrm{C}}$ specific inhibitors in the clinic. However, one notion to be aware of is that cell line-based and mouse models may prove challenging to extrapolate to future clinical studies. Possible toxicities upon combinations of targeted agents are often not easy to predict and can be difficult to identify in preclinical studies. The triple therapeutic approach described above aims to prevent growth signaling pathway reactivation by crosstalk and negative feedback, yet there is no guarantee that it will not be overridden by acquisition of drug resistance due to pre-existing tumor heterogeneity in patients [127]. Therefore, it is likely that other therapeutic paths including immunotherapy, radiotherapy and chemotherapy would need to be integrated.

Further exciting preliminary activity with low frequency of adverse events has been documented for a potent RAF/MEK inhibitor (RO5126766). Patients with KRAS mutant lung adenocarcinomas showed significant treatment benefits, with $60 \%$ of patients showing tumor reductions-of which, $30 \%$ were partial responses [128]. The significant response rate represents one of the first responses to single agent downstream inhibitors to date. A multi-center, dose-escalation, phase I trial is ongoing to 
assess the maximum tolerated dose and the pharmacodynamic activity of the combination RO5126766 plus the FAK inhibitor defactinib in advanced solid tumors including KRAS ${ }^{+}$NSCLC (NCT03875820). Both compounds will be administered orally twice a week for 3 weeks followed by 1 week off, RO5126766 under fasting conditions and defactinib immediately after a meal. A second study aims to test the safety of RO5126766 at different doses for patients with advanced $K R A S^{+}$lung cancer who have previously received treatment with a programmed cell death protein 1 (PD-1) or programmed cell death 1 ligand 1 (PD-L1) inhibitor (NCT03681483).

Recent functional studies demonstrated that the switch region of RAS interacts with a large number of effector proteins with a conserved RAS-binding domain (RBD) [129]. Because RBD-mediated interactions are essential for RAS signaling, blocking RBD association with small molecules offers a promising route to success. One such compound called rigosertib acts as a RAS mimetic and targets RBDs across multiple signaling pathways involving RAF kinases, RALGDS and PI3Ks [129]. This interaction hampers their inability to bind to RAS and subsequently abrogates downstream signaling. The therapeutic efficacy of rigosertib is currently being evaluated in several clinical trials across different types of cancer. A phase I/IIa trial is designed to study the combination of rigosertib plus nivolumab (an immune checkpoint inhibitor) in metastatic $K R A S^{+}$lung adenocarcinoma adult patients who have progressed on standard first-line treatment (NCT04263090). Rigosertib will be dosed twice a day for 21 consecutive days, followed by 7 days off treatment, while nivolumab will be administered twice per 28 day cycle.

\subsection{Second Chance for EGFR-related Signaling in KRAS-driven NSCLC as Therapeutic Benefit}

In wildtype cases, KRAS is activated in response to ligand-activated signaling through ERBB RTKs (Figure 1) [130]. Strikingly, initial clinical trials using first-generation EGFR TKIs erlotinib or gefitinib have demonstrated little or no benefit to patients with KRAS mutations and the presence of mutant KRAS is used as a biomarker to exclude patients for EGFR TKI therapy [75,131-133]. Two meta-analyses suggested that patients with KRAS-mutated tumors exhibited significantly lower response rates with EGFR TKI than those with KRAS wildtype tumors [134,135]. However, in both studies, the KRAS wildtype group harbored EGFR alterations, hindering interpretation of the results. The reason behind the negative treatment interaction between EGFR TKI and KRAS mutant tumors was believed to be that oncogenic mutations in KRAS lock the protein in a constitutively active state, conferring independence from upstream signaling by ERBB RTKs (Figure 1). However, recent data provide evidence that this independence may not be definite: (i) in KRAS mutant NSCLC cell lines, activation of PI3K depends on basal activity of wildtype IGF1R, illustrating a model for how oncogenic and normal signal transduction coordinate [136]; (ii) development of $K R A S^{\mathrm{G} 12 \mathrm{D}}$-driven pancreatic ductal adenocarcinoma is suppressed in the absence of EGFR [137,138]; and (iii) induced expression of ERBB2 and ERBB3 provokes resistance to MEK inhibition in $K R A S^{+}$lung and colorectal cell lines [139].

Two preclinical studies further challenge this dogma, indicating that mutant KRAS demands activation of ERBB receptors to facilitate lung tumorigenesis [140,141]. Multiple ERBB RTKs and several of their ligands are expressed and active from the earliest stage of KRAS-driven tumor development in men and mice [140,141]. Deletion of EGFR in a mouse model of autochthonous lung cancer driven by KRAS ${ }^{G 12 D}$ reduced KRAS activity and transiently retarded tumor growth [140]. However, a rapid resistance mechanism by non-EGFR ERBB family members was observed at late tumor stages. This escape mechanism explains the disappointing outcome of first-generation TKIs and suggests high therapeutic potential of pan-ERBB inhibitors. In fact, the FDA-approved pan-ERBB inhibitor afatinib (as monotherapy) improved overall survival as shown in genetically engineered mouse models and in patient- and cell line-derived xenografts [140], whereas neratinib (another pan-ERBB inhibitor) proved to be highly efficient only in combination with MEK inhibition in an autochthonous tumor setting [141]. This difference in application (single agent vs. combinatorial) may stem from different dosing schedules and/or mouse models used. Taken together, these studies provide a solid ground to re-evaluate the use of pan-ERBB inhibitors in clinical trials in patients with KRAS mutant lung tumors. 


\subsection{Metabolic Rewiring and Autophagy Inhibition}

The reprogramming of cellular metabolism is an important hallmark of cancer typically associated with increased growth demands, and/or compensatory adaptation to mitochondrial defects [142-144]. Mutant KRAS activity causes increased proliferation in multiple models. Hence, it is not surprising that high-grade $K R A S^{+}$lung tumors rely on accelerated glucose metabolism for enhanced antioxidant potential and exhibit increased autophagy and macropinocytosis, relative to non-mutant cells [145-147]. In line, advanced-stage tumors in $K R A S^{G 12 D /+} / p 53^{-/-}$mice were hypersensitive to combined glucose and glutathione depletion, whereas low-grade tumors in the same model, with a glucose metabolism similar to that of normal tissues, failed to respond [33]. Unfortunately, glucose depletion may pose significant toxicity risks in the clinics. An alternative strategy may be targeting of tumor-specific phenotypes associated with the metabolic rewiring. Multiple glycolytic genes are upregulated in NSCLC—some of which correlate with poor prognosis [148-152]. Deletion of hexokinase 2 (Hk2) in lung cancer cells suppressed glucose derived ribonucleotides and impaired glutamine derived carbon utilization in anaplerosis [153]. Its systemic ablation was found to be therapeutic in KRAS ${ }^{G 12 D /+}$ mice bearing lung tumors without adverse physiological consequences. In addition, silencing of pyruvate kinase isoenzyme M2 enhanced the efficacy of docetaxel and cisplatin (an alkylating agent) in human KRAS mutant lung cancer xenograft models [154,155]. Ablation of lactate dehdryogenase-a enzyme (critical for interconversion of pyruvate to lactate and associated with aggressive outcome) repressed the formation of spontaneous KRAS ${ }^{G 12 D}$-driven lung tumors [156].

Autophagy is a catabolic pathway in cells to support metabolism in response to starvation and to clear damaged proteins and organelles. It has also been identified as a survival mechanism across several cancer types [157-160]. The association between tumor cell survival and autophagy can be explained, at least partly by the role of autophagy in protecting cells from undergoing programmed cell death [161]. This provides a logical rationale for why the inhibition of autophagy could improve the response to other agents and forms the basis for completed and ongoing clinical trials for NSCLC (NCT01649947, NCT00728845, NCT01497925, and NCT03057340). In fact, in recent years, inhibition of autophagy has been widely explored as a potential therapeutic intervention for cancer, although the results are somehow contradictory. Tumors with KRAS substitutions were reported to depend on macroautophagy to cope with oncogene-induced metabolic stress in order to facilitate the maintenance of mitochondrial metabolism, cell survival and tumorigenic growth [162,163]. This paradigm has been questioned by the findings of Eng et al. [164]: deletion of autophagy-related 7 potently blocked macroautophagy in several cancer lines with oncogenic KRAS alterations but failed to inhibit cell proliferation in vitro or tumorigenesis in vivo. On the other hand, it has been shown that inhibition of RAF/MEK/ERK cascade activates serine/threonine kinase 11/AMP-activated protein kinase/Unc-51-like autophagy activating kinase 1 (STK11/AMPK/ULK1) signaling axis, leading to autophagy induction [165-167]. This process of cellular recycling protects tumor cells from cytotoxic effects of KRAS pathway blockage. Of note, it is likely that other pathways are also involved in autophagy induction in response to inhibition of RAF/MEK/ERK signaling. Three studies recently published simultaneously illustrated synergistic activity of concomitant inhibition of autophagy and MAPK pathway in patient-derived xenografts of KRAS mutant pancreatic ductal adenocarcinoma, NRAS mutant melanoma and $B-R A F$ mutant colorectal tumor [165-167]. Of clinical relevance, off-label treatment of a patient with metastatic pancreatic ductal adenocarcinoma with the MEK inhibitor trametinib plus hydroxychloroquine (a lysosomotropic agent for autophagy blockage) resulted in 50\% shrinkage in tumor burden without any adverse effects [166]. In line, a phase I trial is recruiting patients with $K R A S^{+}$metastatic pancreatic cancer to study the best dose of hydroxychloroquine when given together with the MEK1/2 inhibitor binimetinib (NCT04132505). Based on these intriguing results, future investigations are required to address the potential therapeutic benefit of combined inhibition of autophagy and MAPK signaling for patients with KRAS-mutated NSCLC.

In light of the role of autophagy inhibition on mitochondrial functionality and tumor maintenance [162,168], direct targeting of mitochondrial activity may also be of therapeutic relevance. 
Disruption of mitochondrial function by loss of mitochondrial transcription factor A hampered KRAS G12D/+ lung tumor formation in mice [169]. Phenformin monotherapy, a mitochondrial complex I inhibitor, has been defined as a selective agent targeting lung tumors in $K R A S^{G 12 D /+} / S T K 11^{-/}$mice; no changes in tumor burden and survival have been observed in $K R A S^{G 12 D /+} / p 53^{-/-}$context [170]. Mutant KRAS tumors also express unique dependencies in terms of fatty acid synthesis and oxidation, tricarboxylic acid cycle (TCA)-dependent glucose metabolism and branched-chain amino acid utilization, which can potentially be exploited therapeutically [145]. However, their metabolic heterogeneity may severely limit the efficacy. Future studies thus are needed to address this therapeutic challenge.

Metabolic communication in tumors also adds a new layer of immunoregulation for immune evasion [171] and its targeting is an encouraging strategy to enhance tumor immunogenicity [172]. Altered metabolic programs affect the fate decision of T cells [173]. However, tumors with distinct metabolic properties may modulate $\mathrm{T}$ cell responses differently, enhancing the chance of resistance to treatment $[145,171,172,174]$. Similarly, agents that target tumor cell metabolism may yield unexpected results due to their potential effects on stroma cells and stroma-tumor cell communication. Future in vivo models will offer invaluable insight onto the evaluation of stromal effects on metabolic targeting and resistance to therapy in $K R A S^{+}$NSCLC.

\subsection{Immunotherapy}

Cancers escape immune surveillance by aberrantly expressing immune checkpoints (e.g., upregulation of the immunosuppressive protein PD-L1) that masks them from the host immune system. Immune checkpoint blockage using monoclonal antibodies against PD-1 and its main ligand PD-L1 has substantially improved the treatment landscape of advanced-stage NSCLC and made its most strong impact in the stage III and first-line stage IV settings [175-178]. This treatment is being progressively incorporated into the first-line armamentarium [179] (NCT02259621, NCT03693326); however, response rates reach only $20 \%$ in unselected patients [180].

The key limitation of the advances in immunotherapy has been the identification of a biomarker for a sensitive and specific prediction of treatment response. Lung cancer patients with $\mathrm{T}$ cell inflamed tumor phenotype and high tumor mutational burden obtain greatest benefits upon exposure to immune checkpoint inhibitors $[57,71,181]$. PD-L1 expression is the only FDA-approved biomarker for these therapies in patients with lung adenocarcinoma but its sensitivity is modest. Studies on the predictive importance of KRAS mutations for the efficacy of immune checkpoint inhibitors have not uniformly provided positive results. Mutant KRAS was associated with increases in tumor infiltrating lymphocytes, PD-L1 expression and tumor mutational burden [182,183]. However, while Gianoncelli et al. observed no significant differences between $K R A S^{+}$and non-KRAS NSCLC patients in terms of progression-free or overall survival [184], Kauffmann-Guerrero et al. reported a positive outcome for KRAS mutations in response to immune checkpoint inhibitors [185]. Molecular diversity within $K R A S^{+}$NSCLC patients offers an attractive biological explanation for such discrepancy in results [186]. In particular, co-alterations in STK11 and $p 53$ (both associated with high tumor mutational burden) profoundly influence the tumor-immune contexture [21]. KRAS/STK11 NSCLC (25\% of KRAS NSCLC) lacked tumor-infiltrating lymphocytes and expressed reduced levels of immune markers and PD-L1. Inactivating somatic mutations in STK11 have thus emerged as a major genomic driver of primary resistance to immune checkpoint inhibitors [187]. Such negative impact extends to tumors with high PD-L1 expression and is further associated with primary resistance to combined PD-L-1/cytotoxic T-lymphocyte associated-protein 4 (CTLA-4) blockage in NSCLC [188]. Simultaneous therapies that reverse the T cell suppressive tumor microenvironment in KRAS/STK11 NSCLC would be required for a potent response. In fact, recent data demonstrated how anti-PD-1 antibodies failed to induce tumor regression in mice without STK11 but exposing them to an interleukin-6 antibody (a pro-inflammatory cytokine secreted by tumor-infiltrating neutrophils) or neutrophil-depleting antibody yielded $\mathrm{T}$ cell infiltration and therapeutic benefits [189]. Similarly, anti-angiogenics and epigenetic modifiers are also needed to be investigated in KRAS/STK11 NSCLC. In addition, mutations in phosphatase and 
tensin homolog (PTEN) and KEAP1 have been nominated as potential drivers of de novo resistance to immune checkpoint inhibition in NSCLC $[188,190]$. Co-mutation in KEAP1 was also associated with shorter duration of initial platinum-based chemotherapy and shorter overall survival from start of immune therapy in $K R A S^{+}$advanced NSCLC [190]. In contrast, KRAS/p53 co-mutated NSCLC was characterized by an inflammatory response, immune-editing and expression of co-stimulatory and co-inhibitor molecules including PD-L1 [187,191]. These observations indicate that this cohort may be particularly susceptible to anti-immune checkpoint therapies. Indeed, KRAS/p53 co-mutations were associated with potent treatment response and improved progression-free and overall survival [187]. Taken together, co-occurring somatic genomic alterations in KRAS ${ }^{+}$NSCLC represent independent predictors for sensitivity to anti-PD-1/PD-L1 therapies. Treatment needs to be individualized and may require the use of rational combinations (e.g., immunotherapy plus conventional therapies targeting RAS downstream cascade or cell cycle inhibitors) for a durable therapy response in KRAS ${ }^{+}$NSCLC [57]. In immune-competent mice, the KRAS ${ }^{\mathrm{G} 12 \mathrm{C}}$ inhibitor AMG 510 resulted in a pro-inflammatory tumor microenvironment and produced durable cures in combination with immune checkpoint inhibitors [111]. Several clinical trials are ongoing. A phase I study evaluates the combination of the CDK4/6 inhibitor abemaciclib with anti-PD-1 antibody pembrolizumab for KRAS mutant, $P D-L 1^{+}$patients with stage IV NSCLC (NCT02779751). A second trial is recruiting patients to determine the side effects and best dose of pembrolizumab and the MEK inhibitor trametinib for recurrent KRAS-mutated NSCLC that is metastatic, unresectable or locally advanced (NCT03299088, NCT03225664). Another phase I study focuses on the safety and tolerability of pembrolizumab infusion in combination with mRNA-5671/V941 (a KRAS vaccine) in patients with KRAS mutant advanced or metastatic NSCLC (NCT03948763). An open-label phase II study aims to assess the safety and efficacy of SHR-1210 (an anti-PD-1 antibody) plus apatinib mesylate (an anti-vascular endothelial growth factor (VEGF) receptor-2 inhibitor) versus pemetrexed (an antimetabolite) and carboplatin (an alkylating agent) in adult patients with KRAS ${ }^{+}$ stage IV NSCLC (NCT03777124). Another phase II trial is underway to determine the effects of combining pembrolizumab with anti-VEGF receptor (ramucirumab), and docetaxel in treating NSCLC patients who failed to respond to FDA-approved treatments with platinum-based chemotherapy administered concurrently or sequentially with anti-PD-1/PD-L1 immunotherapy (NCT04340882).

It is also notable that responsiveness to PD-1/PD-L1 checkpoint blockage correlates with an interferon gamma-inducible gene signature and major histocompatibility complex class II (MHC II) expression by tumor cells [192]. Recent data emphasize the active inhibitory role of epigenetic and ERK signaling cascades in restricting cancer cell-intrinsic MHC II expression in NSCLC and suggest their combinatorial inhibition as new responsiveness to checkpoint therapies [192].

Based on the limitations of both immune and targeted therapies a recent study aimed to combine these two modalities to treat KRAS mutant lung tumors [193]. As opposed to conventional continuous exposure to MEK inhibitors in the clinic, a pulsatile schedule of MEK inhibitors (selumetinib and trametinib) was more effective at controlling tumor progression and altering the tumor microenvironment favorably by enhancing $\mathrm{T}$ cell activation with increased expression of immune checkpoint regulators CTLA-4 and PD-1. Other MEK inhibitors with different potency, target specificity and elimination half-life such as cobimetinib and binimetinib also need to be tested. In vivo data with pulsatile MEK inhibition in a transplantable KRAS model and in a genetically engineered mouse model bearing human $K R A S^{G 12 C}$ substitution were consistent with the ex vivo observations: the pulsatile treatment had a superior anti-tumor activity and delayed drug resistance in comparison with continuous exposure. This effect was further enhanced when combined with CTLA-4 blockage. Such prolonged survival was not present in immune-deficient mice illustrating that it was mediated by the adaptive immune system. These results set the foundation and highlight the importance of a combinatorial therapeutic strategy using pulsatile targeted therapy together with immunotherapy to optimally enhance tumor delay and promote long-term anti-tumor immunity. A similar pulsatile treatment regimen is under clinical evaluation in NSCLC patients with intermittent selumetinib and antibodies targeting CTLA-4 and PD-L1. One drawback, however, is that the trial did not stratify 
for co-existing alterations apart from KRAS. Hence, it is likely that MEK inhibition alone, which targets downstream of KRAS, may not suffice to repress KRAS-driven tumors together with additional alterations, even when combined with immunotherapy.

In addition, Tran et al. reported that infusion of $\mathrm{CD} 8^{+} \mathrm{T}$ cells targeting KRAS ${ }^{G 12 D}$ results in regression of lung metastases and thus mediates effective anti-tumor activity in a patient with metastatic colorectal cancer [194]. This immune response is restricted to the presence of the major histocompatibility complex class I allele HLA-C*08:02: the authors observed progression of one of the lesions when the chromosome 6 haplotype encoding HLA-C*08:02 was lost. Despite the rarity of HLA-C*08:02, the study illustrated the promise of T cell-based immunotherapy for targeting KRASG12D and HLA-C*08:02. Further evaluation in more patients and testing for other KRAS allelic substitutions is needed. A novel clinical trial is recruiting patients to determine the safety of administering peripheral blood lymphocytes transduced with anti-KRAS ${ }^{\mathrm{G} 12 \mathrm{D}}$ murine $\mathrm{T}$ cell receptor (TCR) with preparative lymphodepletion and high dose interleukin-2 (NCT03745326). Its phase II part will focus on whether solid tumors (gastrointestinal, pancreatic, gastric, colon and rectal) will shrink upon treatment. Another trial (NCT04146298) will investigate the safety and activity of adoptive transfer of autologous T cells genetically engineered to express a TCR that targets KRAS ${ }^{G 12 V}$ in the context of HLA-A*11:01 in human leukocyte antigen (LA)-matched patients with advanced pancreatic cancer; the study will also measure the in vivo survival of engineered T cells. Future studies involving anti-mutant KRAS TCR in NSCLC are awaited.

\section{Discussion}

Despite decades of research highlighting mutant KRAS as a central driver of tumorigenesis and clinical resistance, the development of therapeutics potently tackling KRAS aberrations has so far been unaccomplished. In recent years, a variety of efficient and specific chemicals has entered preclinical and early clinical settings. A new wave of attempts is motivated to drug KRAS directly, which has long been considered difficult to target. A striking breakthrough has been achieved with covalent inhibitors such as MRTX849 and AMG 510 as well as with LC-2, a degrader molecule against the endogenous protein, in patients with $K R A S^{G 12 C}$ lung tumors. Conventional (e.g., combined chemotherapy with targeted KRAS downstream agents) and novel tools based on improved understanding of the pathobiology of mutant KRAS (e.g., cellular co-dependencies, association with a vulnerability to immunotherapies) are appealing strategies but demand further clinical testing in patients. Rational combinations may further advance the attempts to target KRAS-driven lung tumors. The reason behind the insufficient benefits of treating $K R A S^{+}$NSCLC patients might be mechanism-related rather than the potency and efficacy of targeting itself. A critical point is the high heterogeneity within $K R A S$ mutant lung tumors. Co-existing genetic events and mutant $K R A S$ allele copy number gains define distinct metabolic profiles and tumor microenvironment, both contributing to differential drug sensitivities in seemingly comparable tumors. Thus, by molecularly tailored stratification in addition to KRAS aberrations we may finally change the course of the deadly NSCLC.

Author Contributions: I.Z.U., H.P.M. and E.C. wrote the manuscript. All authors have read and agreed to the published version of the manuscript.

Funding: This work was supported by the Fund of City of Vienna for innovative, interdisciplinary cancer research (I.Z.U.), by the Comprehensive Cancer Center research grant and the Fellinger Krebsforschungsverein (H.P.M.) and by the Austrian Science Fund (FWF) P 25599, P 32900 and Doc 59-B33 (E.C.).

Acknowledgments: We thank all the members of the lab for their input and critical reading of the manuscript. Open Access Funding by the Austrian Science Fund (FWF).

Conflicts of Interest: The authors declare no conflict of interest. 


\section{Abbreviations}

\begin{tabular}{|c|c|}
\hline A-RAF & V-Raf murine sarcoma 3611 viral oncogene homolog 1 \\
\hline AKT & Protein kinase B \\
\hline ALK & Anaplastic lymphoma receptor tyrosine kinase \\
\hline AMPK & AMP-activated protein kinase \\
\hline $\mathrm{APC} / \mathrm{C}$ & Anaphase-promoting complex/cyclosome \\
\hline ASK1 & Apoptosis signal-regulating kinase 1 \\
\hline ASO & Antisense-oligonucleotide \\
\hline B-RAF & V-Raf murine sarcoma viral oncogene homolog B \\
\hline Bad & BCL2-associated agonist of cell death \\
\hline BCL-XL & B-cell lymphoma-extra large \\
\hline BCL2 & B-cell lymphoma 2 \\
\hline BET & Bromodomain and extraterminal domain \\
\hline BRCA & Breast cancer gene \\
\hline C-RAF & V-Raf-1 murine leukemia viral oncogene-like protein 1 \\
\hline CDC25C & M-phase inducer phosphatase 3 \\
\hline CDK & Cyclin-dependent kinase \\
\hline CDKN2A/B & Cyclin-dependent kinase inhibitor 2A/B \\
\hline Chk1 & Checkpoint kinase 1 \\
\hline CRISPR/Cas9 & Clustered regularly interspaced short palindromic repeats/CRISPR-associated protein 9 \\
\hline CSC & Cancer stem-like cell \\
\hline CTLA-4 & Cytotoxic T-lymphocyte-associated protein 4 \\
\hline DDR1 & Discoidin domain receptor 1 \\
\hline EGFR & Epidermal growth factor receptor \\
\hline ERK & Extracellular regulated kinase \\
\hline FAK & Focal adhesion kinase \\
\hline FDA & U.S. Food and Drug Administration \\
\hline FGFR & Fibroblast growth factor receptor \\
\hline FTI & Farnesyltransferase inhibitor \\
\hline G12C & Glycine 12 to cysteine \\
\hline G12D & Glycine 12 to aspartic acid \\
\hline G12V & Glycine 12 to valine \\
\hline GAP & GTPase-activating protein \\
\hline GATA2 & GATA-binding protein 2 \\
\hline GDP & Guanosine diphosphate \\
\hline GEF & Guanine nucleotide exchange factor \\
\hline GGTase I & Geranylgeranyltransferase I \\
\hline GTP & Guanosine triphosphate \\
\hline HER2-4/ERBB2-4 & Human epidermal growth factor receptors $2-4$ \\
\hline HLA & Human leukocyte antigen \\
\hline HRAS & Harvey rat sarcoma viral oncogene homolog \\
\hline HSP90 & Heat shock protein 90 \\
\hline ICMT1 & Isoprenyl carboxyl methyltransferase \\
\hline IGF1R & Insulin-like growth factor 1 receptor \\
\hline IKK & IkappaB kinase \\
\hline I $\kappa B$ & Nuclear factor of kappa light polypeptide gene enhancer in B-cells inhibitor \\
\hline JNK & c-Jun N-terminal kinase \\
\hline KEAP1 & Kelch-like ECH-associated protein 1 \\
\hline KRAS & Kirsten rat sarcoma viral oncogene homolog \\
\hline LKB1 & Liver kinase B1 \\
\hline MAP3K7 & Mitogen-activated protein kinase kinase kinase 7 \\
\hline MAPK & Mitogen-activated protein kinase \\
\hline MEK & Mitogen-activated protein kinase kinase \\
\hline MHC II & Major histocompatibility complex class II \\
\hline
\end{tabular}


MTOR

NF-KB

NRAS

NSCLC

ORR

p53

p90RSK

PARP

PD-1

PD-L1

PDX

pERK

PFS

PI3K

PLD1

PLK1

PROTAC

PTEN

PTPN11

RAC

RAF

RAL

RALGDS

RBD

RCE1

RET

RHOA

RNAi

ROCK2

ROS

RTK

SNAIL2

SRC

STK11

STK3

TBK1

TCA

TCR

Th17

TIAM1

Tim-3

TKI

TPX2

Treg

ULK1

VHL

WT1
Mechanistic target of rapamycin kinase

Nuclear factor 'kappa-light-chain-enhancer' of activated B-cells

Neuroblastoma rat sarcoma viral oncogene homolog

Non-small-cell lung cancer

Objective response rate

Tumor protein $\mathrm{p} 53$

p90 ribosomal 56 kinase

Poly(ADP-ribose)polymerase

Programmed cell death protein 1

Programmed cell death 1 ligand 1

Patient-derived xenograft

Phosphorylated ERK

Progression-free survival

Phosphoinositide 3-kinase

Phospholipase D1

Polo-like kinase 1

Proteolysis-targeting chimera

Phosphatase and tensin homolog

Protein tyrosine phosphatase non-receptor type 11

Ras-related C3 botulinum toxin substrate 1

Rat fibrosarcoma

Ras-like protein

Ral guanine nucleotide dissociation stimulator

RAS-binding domain

RAS-converting enzyme 1

RET proto-oncogene

Ras homolog family member

RNA interference

Rho-associated coiled-coil containing protein kinase 2

Proto-oncogene tyrosine-protein kinase ROS

Receptor tyrosine kinase

Snail family transcriptional repressor 2

V-Src avian sarcoma (Schmidt-Ruppin A-2) viral oncogene homolog

Serine/threonine kinase 11

Serine/threonine-protein kinase 3

TANK binding kinase 1

Tricarboxylic acid cycle

$\mathrm{T}$ cell receptor

T helper 17

T lymphoma invasion and metastasis-inducing protein 1

T cell immunoglobulin mucin-3

Tyrosine kinase inhibitor

Targeting protein for Xklp2

Regulatory T cells

Unc-51-like autophagy activating kinase 1

von Hippel-Lindau disease tumor suppressor

Wilms tumor 1 


\section{References}

1. Siegel, R.L.; Miller, K.D.; Jemal, A. Cancer statistics, 2019. CA. Cancer J. Clin. 2019, 69, 7-34. [CrossRef] [PubMed]

2. Socinski, M.A.; Evans, T.; Gettinger, S.; Hensing, T.A.; Van Dam Sequist, L.; Ireland, B.; Stinchcombe, T.E. Treatment of stage IV non-small cell lung cancer: Diagnosis and management of lung cancer, 3rd ed: American college of chest physicians evidence-based clinical practice guidelines. Chest 2013, 143, e341S. [CrossRef] [PubMed]

3. Polo, V.; Besse, B. Maintenance strategies in stage IV non-small-cell lung cancer (NSCLC): in which patients, with which drugs? Ann. Oncol. 2013, 25, 1283-1293. [CrossRef] [PubMed]

4. Hildebrandt, M.A.T.; Gu, J.; Wu, X. Pharmacogenomics of platinum-based chemotherapy in NSCLC. Expert Opin. Drug Metab. Toxicol. 2009, 5, 745-755. [CrossRef]

5. Ahmadzada, T.; Kao, S.; Reid, G.; Noyer, M.; Mahar, A.; Cooper, W.A. An Update on Predictive Biomarkers for Treatment Selection in Non-Small Cell Lung Cancer. J. Clin. Med. 2018, 7, 153. [CrossRef]

6. Furugaki, K.; Mochizuki, M.; Kohno, M.; Shu, S.; Harada, N.; Yoshimura, Y. Expression of C-terminal ALK, RET, or ROS1 in lung cancer cells with or without fusion. BMC Cancer 2019, 19, 301. [CrossRef]

7. Cox, A.D.; Fesik, S.W.; Kimmelman, A.C.; Luo, J.; Der, C.J. Drugging the undruggable RAS: Mission possible? Nat. Rev. Drug Discov. 2014, 13, 828-851. [CrossRef]

8. Kranenburg, O. The KRAS oncogene: past, present, and future. Biochim. Biophys. Acta. 2005, 1756, 81-82. [CrossRef]

9. Karnoub, A.E.; Weinberg, R.A. Ras oncogenes: Split personalities. Nat. Rev. Mol. Cell Biol. 2008, 9, 517-531. [CrossRef]

10. Cox, A.D.; Der, C.J. Ras history: The saga continues. Small GTPases 2010, 1, 2-27. [CrossRef]

11. Khosravi-Far, R.; Solski, P.A.; Clark, G.J.; Kinch, M.S.; Der, C.J. Activation of Rac1, RhoA, and mitogen-activated protein kinases is required for Ras transformation. Mol. Cell. Biol. 1995, 15, 6443-6453. [CrossRef] [PubMed]

12. Leevers, S.J.; Paterson, H.F.; Marshall, C.J. Requirement for Ras in Raf activation is overcome by targeting Raf to the plasma membrane. Nature 1994, 369, 411-414. [CrossRef] [PubMed]

13. Gupta, S.; Ramjaun, A.R.; Haiko, P.; Wang, Y.; Warne, P.H.; Nicke, B.; Nye, E.; Stamp, G.; Alitalo, K.; Downward, J. Binding of Ras to Phosphoinositide 3-Kinase p110a Is Required for Ras-Driven Tumorigenesis in Mice. Cell 2007, 129, 957-968. [CrossRef] [PubMed]

14. Rodriguez-Viciana, P.; Warne, P.H.; Khwaj, A.A.; Marte, B.M.; Pappin, D.; Das, P.; Waterfield, M.D.; Ridley, A.; Downward, J. Role of Phosphoinositide 3-OH Kinase in Cell Transformation and Control of the Actin Cytoskeleton by Ras. Cell 1997, 89, 457-467. [CrossRef]

15. Hofer, F.; Fields, S.; Schneider, C.; Martin, G.S. Activated Ras interacts with the Ral guanine nucleotide dissociation stimulator. Proc. Natl. Acad. Sci. USA 1994, 91, 11089-11093. [CrossRef]

16. Bodemann, B.O.; White, M.A. Ral GTPases and cancer: Linchpin support of the tumorigenic platform. Nat. Rev. Cancer 2008, 8, 133-140. [CrossRef]

17. Hobbs, G.A.; Der, C.J.; Rossman, K.L. RAS isoforms and mutations in cancer at a glance. J. Cell Sci. 2016, 129, 1287-1292. [CrossRef]

18. Fernández-Medarde, A.; Santos, E. Ras in cancer and developmental diseases. Genes and Cancer 2011, 2, 344-358. [CrossRef]

19. Dearden, S.; Stevens, J.; Wu, Y.-L.; Blowers, D. Mutation incidence and coincidence in non small-cell lung cancer: meta-analyses by ethnicity and histology (mutMap). Ann. Oncol. 2013, 24, 2371-2376. [CrossRef]

20. Bar-Sagi, D.; Knelson, E.H.; Sequist, L.V. A bright future for KRAS inhibitors. Nat. Cancer 2020, 1, $25-27$. [CrossRef]

21. Skoulidis, F.; Byers, L.A.; Diao, L.; Papadimitrakopoulou, V.A.; Tong, P.; Izzo, J.; Behrens, C.; Kadara, H.; Parra, E.R.; Canales, J.R.; et al. Co-occurring genomic alterations define major subsets of KRAS-mutant lung adenocarcinoma with distinct biology, immune profiles, and therapeutic vulnerabilities. Cancer Discov. 2015, 5, 861-878. [CrossRef] [PubMed]

22. Riely, G.J.; Jordan, E.; Kim, H.R.; Yu, H.A.; Solit, D.B.; Kris, M.G.; Ni, A.; Arcila, M.E.; Ladanyi, M. Association of outcomes and co-occuring genomic alterations in patients with KRAS -mutant non-small cell lung cancer. J. Clin. Oncol. 2016, 3415 SUPPL, 9019. [CrossRef] 
23. El Osta, B.E.; Behera, M.; Kim, S.; Berry, L.D.; Sica, G.; Pillai, R.N.; Owonikoko, T.K.; Kris, M.G.; Johnson, B.E.; Kwiatkowski, D.J.; et al. Characteristics and Outcomes of Patients With Metastatic KRAS-Mutant Lung Adenocarcinomas: The Lung Cancer Mutation Consortium Experience. J. Thorac. Oncol. 2019, 14, 876-889. [CrossRef] [PubMed]

24. Dogan, S.; Shen, R.; Ang, D.C.; Johnson, M.L.; D'Angelo, S.P.; Paik, P.K.; Brozostowski, E.B.; Riely, G.J.; Kris, M.G.; Zakowski, M.F.; et al. Molecular epidemiology of EGFR and KRAS mutations in 3,026 lung adenocarcinomas: Higher susceptibility of women to smoking-related KRAS-mutant cancers. Clin. Cancer Res. 2012, 18, 6169-6177. [CrossRef] [PubMed]

25. El Osta, B.E.; Behera, M.; Kim, S.; Berry, L.D.; Sica, G.; Pillai, R.N.; Owonikoko, T.K.; Kris, M.G.; Johnson, B.E.; Kwiatkowski, D.J.; et al. Characteristics and outcomes of patients (pts) with metastatic KRAS mutant lung adenocarcinomas: Lung Cancer Mutation Consortium (LCMC) database. J. Clin. Oncol. 2017, 35 15 SUPPL, 9021. [CrossRef]

26. Redig, A.J.; Chambers, E.S.; Lydon, C.A.; Dahlberg, S.E.; Alden, R.S.; Janne, P.A. Genomic complexity in KRAS mutant non-small cell lung cancer (NSCLC) from never/light-smokers v smokers. J. Clin. Oncol. 2016, 34) 15 SUPPL, 9087. [CrossRef]

27. Muñoz-Maldonado, C.; Zimmer, Y.; Medová, M. A comparative analysis of individual ras mutations in cancer biology. Front. Oncol. 2019, 9, 1088. [CrossRef]

28. Ihle, N.T.; Byers, L.A.; Kim, E.S.; Sintigny, P.; Lee, J.J.; Blumenschein, G.R.; Tsao, A.; Liu, S.; Larsen, J.E.; Wang, J.; et al. Effect of KRAS oncogene substitutions on protein behavior: Implications for signaling and clinical outcome. J. Natl. Cancer Inst. 2012, 104, 228-239. [CrossRef]

29. Nadal, E.; Chen, G.; Prensner, J.R.; Shiratsuchi, H.; Sam, C.; Zhao, L.; Kalemkerian, G.P.; Brenner, D.; Lin, J.; Reddy, R.M.; et al. KRAS-G12C mutation is associated with poor outcome in surgically resected lung adenocarcinoma. J. Thorac. Oncol. 2014, 9, 1513-1522. [CrossRef]

30. Shepherd, F.A.; Domerg, C.; Hainaut, P.; Jänne, P.A.; Pignon, J.P.; Graziano, S.; Douillard, J.-Y.; Brambilla, E.; Chevalier, T.L.; Seymour, L.; et al. Pooled analysis of the prognostic and predictive effects of KRAS mutation status and KRAS mutation subtype in early-stage resected non-small-cell lung cancer in four trials of adjuvant chemotherapy. J. Clin. Oncol. 2013, 31, 2173-2181. [CrossRef]

31. Yu, H.A.; Sima, C.S.; Shen, R.; Kass, S.; Gainor, J.; Shaw, A.; Hame, S.M.; Iam, S.W.; Aston, J.; Lovly, C.M.; et al. Prognostic impact of KRAS mutation subtypes in 677 patients with metastatic lung adenocarcinomas. J. Thorac. Oncol. 2015, 10, 431-437. [CrossRef] [PubMed]

32. Kimmelman, A.C. Metabolic dependencies in RAS-driven cancers. Clin. Cancer Res. 2015, 21, $1828-1834$. [CrossRef] [PubMed]

33. Kerr, E.M.; Gaude, E.; Turrell, F.K.; Frezza, C.; Martins, C.P. Mutant Kras copy number defines metabolic reprogramming and therapeutic susceptibilities. Nature 2016, 531, 110-113. [CrossRef] [PubMed]

34. Lindsay, C.R.; Jamal-Hanjani, M.; Forster, M.; Blackhall, F. KRAS: Reasons for optimism in lung cancer. Eur. J. Cancer 2018, 99, 20-27. [CrossRef]

35. Cox, A.D.; Der, C.J.; Philips, M.R. Targeting RAS Membrane Association: Back to the Future for Anti-RAS Drug Discovery? Clin. Cancer Res. 2015, 21, 1819-1827. [CrossRef]

36. Adjei, A.A.; Mauer, A.; Bruzek, L.; Marks, R.S.; Hillman, S.; Geyer, S.; Hanson, L.J.; Wright, J.J.; Erlichman, C.; Kaufmann, S.H.; et al. Phase II study of the farnesyl transferase inhibitor R115777 in patients with advanced non-small-cell lung cancer. J. Clin. Oncol. 2003, 21, 1760-1766. [CrossRef]

37. Kim, E.S.; Kies, M.S.; Fossella, F.V.; Glisson, B.S.; Zaknoen, S.; Statkevich, P.; Munden, R.F.; Summey, C.; Pisters, K.M.W.; Papadimitrakopoulou, V.; et al. Phase II study of the farnesyltransferase inhibitor lonafarnib with paclitaxel in patients with taxane-refractory/resistant nonsmall cell lung carcinoma. Cancer 2005, 104, 561-569. [CrossRef]

38. Rowell, C.A.; Kowalczyk, J.J.; Lewis, M.D.; Garcia, A.M. Direct demonstration of geranylgeranylation and farnesylation of Ki-Ras in vivo. J. Biol. Chem. 1997, 272, 14093-14097. [CrossRef]

39. Whyte, D.B.; Kirschmeier, P.; Hockenberry, T.N.; Nunew-Oliva, I.; James, L.; Catino, J.J.; Bishop, W.R.; Pai, J.K. $\mathrm{K}$ - and N-Ras are geranylgeranylated in cells treated with farnesyl protein transferase inhibitors. J. Biol. Chem. 1997, 272, 14459-14464. [CrossRef]

40. Lobell, R.B.; Liu, D.; Buser, C.A.; Davide, J.P.; DePuy, E.; Hamilton, K.; Koblan, K.S.; Lee, Y.; Mosser, S.; Motzel, S.L.; et al. Preclinical and clinical pharmacodynamic assessment of L-778,123, a dual inhibitor of farnesyl:protein transferase and geranylgeranyl:protein transferase type-I. Mol. Cancer Ther. 2002, 1, 747-758. 
41. Riely, G.J.; Johnson, M.L.; Medina, C.; Rizvi, N.A.; Miller, V.A.; Kris, M.G.; Pietanza, M.C.; Azzoli, C.G.; Krug, L.M.; Pao, W.; et al. A phase II trial of Salirasib in patients with lung adenocarcinomas with KRAS mutations. J. Thorac. Oncol. 2011, 6, 1435-1437. [CrossRef] [PubMed]

42. Rotblat, B.; Ehrlich, M.; Haklai, R.; Kloog, Y. The Ras inhibitor farnesylthiosalicylic acid (Salirasib) disrupts the spatiotemporal localization of active Ras: a potential treatment for cancer. Methods Enzymol. 2008, 439, 467-489. [PubMed]

43. Zundelevich, A.; Elad-Sfadia, G.; Haklai, R.; Kloog, Y. Suppression of lung cancer tumor growth in a nude mouse model by the Ras inhibitor salirasib (farnesylthiosalicylic acid). Mol. Cancer Ther. 2007, 6, 1765-1773. [CrossRef] [PubMed]

44. Wahlstrom, A.M.; Cutts, B.A.; Karlsson, C.; Andersson, K.M.E.; Liu, M.; Sjogren, A.-K.M.; Swolin, B.; Young, S.G.; Bergo, M.O. Rce1 deficiency accelerates the development of K-RAS-induced myeloproliferative disease. Blood 2007, 109, 763-768. [CrossRef]

45. Wahlstrom, A.M.; Cutts, B.A.; Liu, M.; Lindskog, A.; Karlsson, C.; Sjogren, A.-K.M.; Andersson, K.M.E.; Young, S.G.; Bergo, M.O. Inactivating Icmt ameliorates K-RAS-induced myeloproliferative disease. Blood 2008, 112, 1357-1365. [CrossRef]

46. Court, H.; Amoyel, M.; Hackman, M.; Lee, K.E.; Xu, R.; Miller, G.; Bar-Sagi, D.; Bach, E.A.; Bergö, M.O.; Philips, M.R. Isoprenylcysteine carboxylmethyltransferase deficiency exacerbates KRAS-driven pancreatic neoplasia via Notch suppression. J. Clin. Invest. 2013, 123, 4681-4694. [CrossRef]

47. Majmudar, J.D.; Hodges-Loaiza, H.B.; Hahne, K.; Donelson, J.L.; Song, J.; Shrestha, L.; Harrison, M.L.; Hrycyna, C.A.; Gibbs, R.A. Amide-modified prenylcysteine based Icmt inhibitors: Structure-activity relationships, kinetic analysis and cellular characterization. Bioorg. Med. Chem. 2012, 20, 283-295. [CrossRef]

48. Manandhar, S.P.; Hildebrandt, E.R.; Schmidt, W.K. Small-molecule inhibitors of the Rce1p CaaX protease. J. Biomol. Screen 2007, 12, 983-993. [CrossRef]

49. Winter-Vann, A.M.; Baron, R.A.; Wong, W.; Dela Cruz, J.; York, J.D.; Gooden, D.M.; Bergo, M.O.; Young, S.G.; Toone, E.J.; Casey, P.J. A small-molecule inhibitor of isoprenylcysteine carboxyl methyltransferase with antitumor activity in cancer cells. Proc. Natl. Acad. Sci. USA 2005, 102, 4336-4341. [CrossRef]

50. Bridges, C.B. The Origin of Variations in Sexual and Sex-Limited Characters. Am. Nat. 1922, 56, 51-63. [CrossRef]

51. Dobzhansky, T. Genetics of natural populations; recombination and variability in populations of Drosophila pseudoobscura. Genetics 1946, 31, 269-290. [PubMed]

52. Farmer, H.; McCabe, H.; Lord, C.J.; Tutt, A.N.J.; Johnson, D.A.; Richardson, T.B.; Santarosa, M.; Dillon, K.J.; Hickson, I.; Knights, C.; et al. Targeting the DNA repair defect in BRCA mutant cells as a therapeutic strategy. Nature 2005, 434, 917-921. [CrossRef] [PubMed]

53. Balmaña, J.; Domchek, S.M.; Tutt, A.; Garber, J.E. Stumbling blocks on the path to personalized medicine in breast cancer: The case of PARP inhibitors for BRCA1/2 -associated cancers. Cancer Discov. 2011, 1, 29-34. [CrossRef] [PubMed]

54. Barbie, D.A.; Tamayo, P.; Boehm, J.S.; Kim, S.Y.; Moody, S.E.; Dunn, I.A.; Schinzel, A.C.; Sandy, P.; Meylan, E.; Scholl, C.; et al. Systematic RNA interference reveals that oncogenic KRAS-driven cancers require TBK1. Nature 2009, 462, 108-112. [CrossRef] [PubMed]

55. Kumar, M.S.; Hancock, D.C.; Molina-Arcas, M.; Steckel, M.; East, P.; Diefenbacher, M.; Armenteros-Monterroso, E.; Lassailly, F.; Matthews, N.; Nye, E.; et al. The GATA2 transcriptional network is requisite for RAS oncogene-driven non-small cell lung cancer. Cell 2012, 149, 642-655. [CrossRef]

56. Steckel, M.; Molina-Arcas, M.; Weigelt, B.; Marani, M.; Warne, P.H.; Kuznetsov, H.; Kelly, G.; Saunders, B.; Howell, M.; Downward, J.; et al. Determination of synthetic lethal interactions in KRAS oncogene-dependent cancer cells reveals novel therapeutic targeting strategies. Cell Res. 2012, 22, 1227-1245. [CrossRef]

57. Ferrer, I.; Zugazagoitia, J.; Herbertz, S.; John, W.; Paz-Ares, L.; Schmid-Bindert, G. KRAS-Mutant non-small cell lung cancer: From biology to therapy. Lung Cancer 2018, 124, 53-64. [CrossRef]

58. Downward, J. RAS Synthetic Lethal Screens Revisited: Still Seeking the Elusive Prize? Clin. Cancer Res. 2015, 21, 1802-1809. [CrossRef]

59. Scholl, C.; Fröhling, S.; Dunn, I.F.; Schinzel, A.C.; Barbie, D.A.; Kim, S.Y.; Silver, S.J.; Tamayo, P.; Wadlow, R.C.; Ramaswamy, S.; et al. Synthetic Lethal Interaction between Oncogenic KRAS Dependency and STK33 Suppression in Human Cancer Cells. Cell 2009, 137, 821-834. [CrossRef] 
60. Luo, T.; Masson, K.; Jaffe, J.D.; Silkworth, W.; Ross, N.T.; Scherer, C.A.; Scholl, C.; Fröhling, S.; Carr, S.A.; Stern, A.M.; et al. STK33 kinase inhibitor BRD-8899 has no effect on KRAS-dependent cancer cell viability. Proc. Natl. Acad. Sci. USA 2012, 109, 2860-2865. [CrossRef]

61. Shen, S.; Mao, C.-Q.; Yang, X.-Z.; Du, X.-J.; Liu, Y.; Zhu, Y.-H.; Wang, J. Cationic lipid-assisted polymeric nanoparticle mediated GATA2 siRNA delivery for synthetic lethal therapy of KRAS mutant non-small-cell lung carcinoma. Mol. Pharm. 2014, 11, 2612-2622. [CrossRef] [PubMed]

62. Tessema, M.; Yingling, C.M.; Snider, A.M.; Do, K.; Juri, D.E.; Picchi, M.A.; Zhang, X.; Liu, Y.; Leng, S.; Tellez, C.S.; et al. GATA2 is epigenetically repressed in human and mouse lung tumors and is not requisite for survival of KRAS mutant lung cancer. J. Thorac. Oncol. 2014, 9, 784-793. [CrossRef] [PubMed]

63. Litvak, A.M.; Drilon, A.E.; Rekhtman, N.; Pietanza, M.C.; Chaft, J.E.; Woo, K.; Paik, P.K.; Kris, M.G.; Riely, G.J. Phase II trial of bortezomib in KRAS G12D mutant lung cancers. J. Clin. Oncol. 2015, 3315 SUPPL, e19002. [CrossRef]

64. Drilon, A.; Schoenfeld, A.J.; Arbour, K.C.; Litvak, A.; Ni, A.; Montecalvi, J.; Yu, H.A.; Panora, E.; Ahn, L.; Kennedy, M.; et al. Exceptional responders with invasive mucinous adenocarcinomas: a phase 2 trial of bortezomib in patients with KRAS G12D-mutant lung cancers. Cold Spring Harb. Mol. case Stud. 2019, 5, a003665. [CrossRef] [PubMed]

65. Corcoran, R.B.; Cheng, K.A.; Hata, A.N.; Faber, A.C.; Ebi, H.; Coffee, E.M.; Greninger, P.; Brown, R.D.; Godfrey, J.T.; Cohoon, T.J.; et al. Synthetic Lethal Interaction of Combined BCL-XL and MEK Inhibition Promotes Tumor Regressions in KRAS Mutant Cancer Models. Cancer Cell 2013, 23, 121-128. [CrossRef]

66. Ambrogio, C.; Gómez-López, G.; Falcone, M.; Vidal, A.; Nadal, E.; Crosetto, N.; Blasco, R.B.; Fernández-Marcos, P.J.; Sánchez-Céspedes, M.; Ren, X.; et al. Combined inhibition of DDR1 and Notch signaling is a therapeutic strategy for KRAS-driven lung adenocarcinoma. Nat. Med. 2016, 22, 270-277. [CrossRef]

67. Puyol, M.; Martín, A.; Dubus, P.; Mulero, F.; Pizcueta, P.; Khan, G.; Guerra, C.; Santamaría, D.; Barbacid, M. A Synthetic Lethal Interaction between K-Ras Oncogenes and Cdk4 Unveils a Therapeutic Strategy for Non-small Cell Lung Carcinoma. Cancer Cell 2010, 18, 63-73. [CrossRef]

68. Patnaik, A.; Rosen, L.S.; Tolaney, S.M.; Tolcher, A.W.; Goldman, J.W.; Gandhi, L.; Papadopoulos, K.P.; Beeram, M.; Rasco, D.W.; Hilton, J.F.; et al. Efficacy and safety of Abemaciclib, an inhibitor of CDK4 and CDK6, for patients with breast cancer, non-small cell lung cancer, and other solid tumors. Cancer Discov. 2016, 6, 740-753. [CrossRef]

69. Goldman, J.W.; Shi, P.; Reck, M.; Paz-Ares, L.; Koustenis, A.; Hurt, K.C. Treatment Rationale and Study Design for the JUNIPER Study: A Randomized Phase III Study of Abemaciclib With Best Supportive Care Versus Erlotinib With Best Supportive Care in Patients With Stage IV Non-Small-Cell Lung Cancer With a Detectable KRAS Mutation Whose Disease Has Progressed After Platinum-Based Chemotherapy. Clin. Lung Cancer 2016, 17, 80-84.

70. $\quad$ Dietlein, F.; Kalb, B.; Jokic, M.; Noll, E.M.; Strong, A.; Tharun, L.; Ozretić, L.; Künstlinger, H.; Kambartel, K.; Randerath, W.J.; et al. A Synergistic Interaction between Chk1- and MK2 Inhibitors in KRAS-Mutant Cancer. Cell 2015, 162, 146-159. [CrossRef]

71. Yang, H.; Liang, S.-Q.; Schmid, R.A.; Peng, R.-W. New horizons in KRAS-mutant lung cancer: Dawn after darkness. Front. Oncol. 2019, 9, 953. [CrossRef] [PubMed]

72. Drosten, M.; Barbacid, M. Targeting the MAPK Pathway in KRAS-Driven Tumors. Cancer Cell 2020, 37, 543-550. [CrossRef] [PubMed]

73. Blumenschein, G.R., Jr.; Saintigny, P.; Liu, S.; Kim, E.S.; Tsao, A.S.; Herbst, R.S.; Alden, C.; Lee, J.J.; Tang, X.; Stewart, D.J.; et al. Comprehensive biomarker analysis and final efficacy results of sorafenib in the BATTLE (Biomarker-Integrated Approaches of Targeted Therapy for Lung Cancer Elimination) trial. Clin. Cancer Res. 2013, 19, 6967-6975.

74. Dingemans, A.-M.C.; Mellema, W.W.; Groen, H.J.M.; Van Wijk, A.; Burgers, S.A.; Kunst, P.W.A.; Thunnissen, E.; Heideman, D.A.M.; Smit, E.F. A phase II study of sorafenib in patients with platinum-pretreated, advanced (Stage IIIb or IV) non-small cell lung cancer with a KRAS mutation. Clin. Cancer Res. 2013, 19, 743-751. [CrossRef] 
75. Papadimitrakopoulou, V.; Lee, J.J.; Wistuba, I.I.; Tsao, A.S.; Fossella, F.V.; Kalhor, N.; Gupta, S.; Byers, L.A.; Izzo, J.G.; Gettinger, S.N.; et al. The BATTLE-2 study: A biomarker-integrated targeted therapy study in previously treated patients with advanced non-small-cell lung cancer. J. Clin. Oncol. 2016, 34, 3638-3647. [CrossRef]

76. Paz-Ares, L.; Hirsh, V.; Zhang, L.; De Marinis, F.; Yang, J.C.-H.; Wakelee, H.A.; Seto, T.; Wu, Y.L.; Novello, S.; Juhász, E.; et al. Monotherapy Administration of Sorafenib in Patients with Non-Small Cell Lung Cancer (MISSION) Trial: A Phase III, Multicenter, Placebo-Controlled Trial of Sorafenib in Patients with Relapsed or Refractory Predominantly Nonsquamous Non-Small-Cell Lung Cancer after 2 or 3 Previous Treatment Regimens. J. Thorac. Oncol. 2015, 10, 1745-1753.

77. Blasco, R.B.; Francoz, S.; Santamaría, D.; Cañamero, M.; Dubus, P.; Charron, J.; Baccarini, M.; Barbacid, M. C-Raf, but Not B-Raf, Is Essential for Development of K-Ras Oncogene-Driven Non-Small Cell Lung Carcinoma. Cancer Cell 2011, 19, 652-663. [CrossRef]

78. Karreth, F.A.; Frese, K.K.; DeNicola, G.M.; Baccarini, M.; Tuveson, D.A. C-Raf is required for the initiation of lung cancer by K-Ras G12D. Cancer Discov. 2011, 1, 128-136. [CrossRef]

79. Sanclemente, M.; Francoz, S.; Esteban-Burgos, L.; Bousquet-Mur, E.; Djurec, M.; Lopez-Casas, P.P.; Hidalgo, M.; Guerra, C.; Drosten, M.; Musteanu, M.; et al. c-RAF Ablation Induces Regression of Advanced Kras/Trp53 Mutant Lung Adenocarcinomas by a Mechanism Independent of MAPK Signaling. Cancer Cell 2018, 33, 217-228. [CrossRef]

80. Gu, S.; Cui, D.; Chen, X.; Xiong, X.; Zhao, Y. PROTACs: An Emerging Targeting Technique for Protein Degradation in Drug Discovery. Bioessays 2018, 40, e1700247. [CrossRef]

81. Yaeger, R.; Corcoran, R.B. Targeting Alterations in the RAF-MEK Pathway. Cancer Discov. 2019, 9, 329-341. [CrossRef] [PubMed]

82. Lito, P.; Saborowski, A.; Yue, J.; Solomon, M.; Joseph, E.; Gadal, S.; Saborowski, M.; Kastenhuber, E.; Fellmann, C.; Ohara, K.; et al. Disruption of CRAF-mediated MEK activation is required for effective MEK inhibition in KRAS mutant tumors. Cancer Cell 2014, 25, 697-710. [CrossRef] [PubMed]

83. Carter, C.A.; Rajan, A.; Keen, C.; Szabo, E.; Khozin, S.; Thomas, A.; Brzezniak, C.; Guha, U.; Doyle, L.A.; Steinberg, S.M.; et al. Selumetinib with and without erlotinib in KRAS mutant and KRAS wild-type advanced nonsmall-cell lung cancer. Ann. Oncol. 2016, 27, 693-699. [CrossRef]

84. Hainsworth, J.D.; Cebotaru, C.L.; Kanarev, V.; Ciuleanu, T.E.; Damyanov, D.; Stella, P.; Ganchev, H.; Pover, G.; Morris, C.; Tzekova, V. A phase II, open-label, randomized study to assess the efficacy and safety of AZD6244 (ARRY-142886) versus pemetrexed in patients with non-small cell lung cancer who have failed one or two prior chemotherapeutic regimens. J. Thorac. Oncol. 2010, 5, 1630-1636. [CrossRef]

85. Jänne, P.A.; Shaw, A.T.; Pereira, J.R.; Jeannin, G.; Vansteenkist, J.; Barrios, C.; Franke, F.A.; Grinsted, L.; Zazulina, V.; Smith, P.; et al. Selumetinib plus docetaxel for KRAS-mutant advanced non-small-cell lung cancer: A randomised, multicentre, placebo-controlled, phase 2 study. Lancet Oncol. 2013, 14, 38-47.

86. Jänne, P.A.; Van Den Heuvel, M.M.; Barlesi, F.; Cobo, M.; Mazieres, J.; Crinò, L.; Orlov, S.; Blackhall, F.; Wolf, J.; Garrido, P.; et al. Selumetinib plus docetaxel compared with docetaxel alone and progression-free survival in patients with KRAS-mutant advanced non-small cell lung cancer: The SELECT-1 randomized clinical trial. J. Am. Med. Assoc. 2017, 317, 1844-1853. [CrossRef]

87. Chen, Z.; Cheng, K.; Walton, Z.; Wang, Y.; Ebi, H.; Shimamura, T.; Liu, Y.; Tupper, T.; Ouyang, J.; Li, J.; et al. A murine lung cancer co-clinical trial identifies genetic modifiers of therapeutic response. Nature 2012, 483, 613-617. [CrossRef]

88. Blumenschein, G.R., Jr.; Smit, E.F.; Planchard, D.; Kim, D.-W.; Cadranel, J.; De Pas, T.; Dunphy, F.; Udud, K.; Ahn, M.-J.; Hanna, N.H.; et al. A randomized phase II study of the MEK1/MEK2 inhibitor trametinib (GSK1120212) compared with docetaxel in KRAS-mutant advanced non-small-cell lung cancer (NSCLC). Ann. Oncol. Off. J. Eur. Soc. Med. Oncol. 2015, 26, 894-901. [CrossRef]

89. Gadgeel, S.M.; Miao, J.; Riess, J.W.; Mack, P.C.; Gerstner, G.J.; Burns, T.F.; Taj, A.; Akerley, W.L.; Dragnev, K.H.; Moon, J.; et al. S1507: Phase II study of docetaxel and trametinib in patients with G12C or non-G12C KRAS mutation positive (+) recurrent non-small cell lung cancer (NSCLC). J. Clin. Oncol. 2019, 3715 SUPPL, 9021. [CrossRef]

90. Castellano, E.; Downward, J. Ras interaction with PI3K: More than just another effector pathway. Genes and Cancer 2011, 2, 261-274. [CrossRef] 
91. Salt, M.B.; Bandyopadhyay, S.; McCormick, F. Epithelial-to-mesenchymal transition rewires the molecular path to PI3K-dependent proliferation. Cancer Discov. 2014, 4, 186-199. [CrossRef] [PubMed]

92. Misale, S.; Fatherree, J.P.; Cortez, E.; Li, C.; Bilton, S.; Timonina, D.; Myers, D.T.; Lee, D.; Gomez-Caraballo, M.; Greenberg, M.; et al. KRAS G12C NSCLC models are sensitive to direct targeting of KRAS in combination with PI3K inhibition. Clin. Cancer Res. 2019, 25, 796-807. [CrossRef] [PubMed]

93. Riely, G.J.; Brahmer, J.R.; Planchard, D.; Crinò, L.; Doebele, R.C.; Mas Lopez, L.A.; Gettinger, S.N.; Schumann, C.; Li, X.; Atkins, B.M.; et al. A randomized discontinuation phase II trial of ridaforolimus in non-small cell lung cancer (NSCLC) patients with KRAS mutations. J. Clin. Oncol. 2012, 3015 SUPPL, 7531. [CrossRef]

94. Tolcher, A.W.; Patnaik, A.; Papadopoulos, K.P.; Rasco, D.W.; Becerra, C.R.; Allred, A.J.; Orford, K.; Aktan, G.; Ferron-Brady, G.; Ibrahim, N.; et al. Phase I study of the MEK inhibitor trametinib in combination with the AKT inhibitor afuresertib in patients with solid tumors and multiple myeloma. Cancer Chemother. Pharmacol. 2015, 75, 183-189. [CrossRef] [PubMed]

95. Mita, M.; Fu, S.; Piha-Paul, S.A.; Janku, F.; Mita, A.; Natale, R.; Guo, W.; Zhao, C.; Kurzrock, R.; Naing, A. Phase I trial of MEK 1/2 inhibitor pimasertib combined with mTOR inhibitor temsirolimus in patients with advanced solid tumors. Invest. New Drugs 2017, 35, 616-626. [CrossRef] [PubMed]

96. Schram, A.M.; Gandhi, L.; Mita, M.M.; Damstrup, L.; Campana, F.; Hidalgo, M.; Grande, E.; Hyman, D.M.; Heist, R.S. A phase $\mathrm{Ib}$ dose-escalation and expansion study of the oral MEK inhibitor pimasertib and PI3K/MTOR inhibitor voxtalisib in patients with advanced solid tumours. Br. J. Cancer 2018, 119, 1471-1476. [CrossRef]

97. Konstantinidou, G.; Ramadori, G.; Torti, F.; Kangasniemi, K.; Ramirez, R.E.; Cai, Y.; Behrens, C.; Dellinger, M.T.; Brekken, R.A.; Wistuba, I.I.; et al. RHOA-FAK is a required signaling axis for the maintenance of KRAS-driven lung adenocarcinomas. Cancer Discov. 2013, 3, 444-457. [CrossRef]

98. Gerber, D.E.; Ross Camidge, D.; Morgensztern, D.; Cetnar, J.; Kelly, R.J.; Ramalingam, S.S.; Spigel, D.R.; Jeong, W.; Scaglioni, P.P.; Zhang, S.; et al. Phase 2 study of the focal adhesion kinase inhibitor defactinib (VS-6063) in previously treated advanced KRAS mutant non-small cell lung cancer. Lung Cancer 2020, 139, 60-67. [CrossRef]

99. Mak, G.; Soria, J.-C.; Blagden, S.P.; Plummer, R.; Fleming, R.A.; Nebot, N.; Zhang, J.; Mazumdar, J.; Rogan, D.; Gazzah, A.; et al. A phase Ib dose-finding, pharmacokinetic study of the focal adhesion kinase inhibitor GSK2256098 and trametinib in patients with advanced solid tumours. Br. J. Cancer. 2019, 120, 975-981. [CrossRef]

100. Park, K.-S.; Yang, H.; Choi, J.; Seo, S.; Kim, D.; Lee, C.H.; Jeon, H.; Kim, S.-W.; Lee, D.H. The HSP90 inhibitor, NVP-AUY922, attenuates intrinsic PI3K inhibitor resistance in KRAS-mutant non-small cell lung cancer. Cancer Lett. 2017, 406, 47-53. [CrossRef]

101. Park, K.-S.; Oh, B.; Lee, M.H.; Jin, H.R.; Nam, K.-Y.; Yang, H.; Choi, Y.; Kim, S.-W.; Lee, D.H. The HSP90 inhibitor, NVP-AUY922, sensitizes KRAS-mutant non-small cell lung cancer with intrinsic resistance to MEK inhibitor, trametinib. Cancer Lett. 2016, 372, 75-81. [CrossRef] [PubMed]

102. Le, H.T.; Nguyen, H.T.; Min, H.-Y.; Hyun, S.Y.; Kwon, S.; Lee, Y.; Van Le, T.H.; Lee, J.; Park, J.H.; Lee, H.-Y. Panaxynol, a natural Hsp90 inhibitor, effectively targets both lung cancer stem and non-stem cells. Cancer Lett. 2018, 412, 297-307. [CrossRef] [PubMed]

103. Chatterjee, S.; Huang, E.H.-B.; Christie, I.; Kurland, B.F.; Burns, T.F. Acquired resistance to the Hsp90 inhibitor, ganetespib, in KRAS-Mutant NSCLC is mediated via reactivation of the ERK-p90RSK-mTOR signaling network. Mol. Cancer Ther. 2017, 16, 793-804. [CrossRef] [PubMed]

104. Chatterjee, S.; Huang, E.H.-B.; Christie, I.; Burns, T.F. Reactivation of the p90RSK-CDC25C pathway leads to bypass of the ganetespib-induced G2-M arrest and mediates acquired resistance to ganetespib in KRAS-mutant NSCLC. Mol. Cancer Ther. 2017, 16, 1658-1668. [CrossRef] [PubMed]

105. Ostrem, J.M.L.; Shokat, K.M. Direct small-molecule inhibitors of KRAS: from structural insights to mechanism-based design. Nat. Rev. Drug Discov. 2016, 15, 771-785. [CrossRef] [PubMed]

106. Lim, S.M.; Westover, K.D.; Ficarro, S.B.; Harrison, R.A.; Choi, H.G.; Pacold, M.E.; Carrasco, M.; Hunter, J.; Kim, N.D.; Xie, T.; et al. Therapeutic targeting of oncogenic K-Ras by a covalent catalytic site inhibitor. Angew. Chem. Int. Ed. Engl. 2014, 53, 199-204. [CrossRef]

107. Ostrem, J.M.; Peters, U.; Sos, M.L.; Wells, J.A.; Shokat, K.M. K-Ras(G12C) inhibitors allosterically control GTP affinity and effector interactions. Nature 2013, 503, 548-551. [CrossRef] 
108. Lito, P.; Solomon, M.; Li, L.S.; Hansen, R.; Rosen, N. Cancer therapeutics: Allele-specific inhibitors inactivate mutant KRAS G12C by a trapping mechanism. Science 2016, 351, 604-608. [CrossRef]

109. Patricelli, M.P.; Janes, M.R.; Li, L.-S.; Hansen, R.; Peters, U.; Kessler, L.V.; Chen, Y.; Kucharski, J.M.; Feng, J.; Ely, T.; et al. Selective inhibition of oncogenic KRAS output with small molecules targeting the inactive state. Cancer Discov. 2016, 6, 316-329. [CrossRef]

110. Janes, M.R.; Zhang, J.; Li, L.-S.; Hansen, R.; Peters, U.; Guo, X.; Chen, Y.; Babbar, A.; Firdaus, S.J.; Darjania, L. Targeting KRAS Mutant Cancers with a Covalent G12C-Specific Inhibitor. Cell 2018, 172, 578-589. [CrossRef]

111. Canon, J.; Rex, K.; Saiki, A.Y.; Mohr, C.; Cooke, K.; Bagal, D.; Gaida, K.; Holt, T.; Knutson, C.G.; Koppada, N.; et al. The clinical KRAS(G12C) inhibitor AMG 510 drives anti-tumour immunity. Nature 2019, 575, 217-223. [CrossRef] [PubMed]

112. Hallin, J.; Engstrom, L.D.; Hargi, L.; Calinisan, A.; Aranda, R.; Briere, D.M.; Sudhakar, N.; Bowcut, V.; Baer, B.R.; Ballard, J.A.; et al. The KRASG12C inhibitor MRTX849 provides insight toward therapeutic susceptibility of KRAS-mutant cancers in mouse models and patients. Cancer Discov. 2020, 10, 54-71. [CrossRef] [PubMed]

113. Seton-Rogers, S. KRAS-G12C in the crosshairs. Nat. Rev. Cancer 2020, 20, 3. [CrossRef] [PubMed]

114. Ryan, M.B.; Fece de la Cruz, F.; Phat, S.; Myers, S.T.; Wong, W.; Shahzade, H.A.; Hong, C.B.; Corcoran, R.B. Vertical Pathway Inhibition Overcomes Adaptive Feedback Resistance to KRAS G12C Inhibition. Clin. Cancer Res. 2020, 26, 1633-1643. [CrossRef]

115. Xue, J.Y.; Zhao, Y.; Aronowitz, J.; Mai, T.T.; Vides, A.; Qeriqi, B.; Kim, D.; Li, C.; De Stanchina, E.; Mazutis, L.; et al. Rapid non-uniform adaptation to conformation-specific KRAS(G12C) inhibition. Nature 2020, 577, 421-425. [CrossRef]

116. Ross, S.J.; Revenko, A.S.; Hanson, L.L.; Ellston, R.; Staniszewska, A.; Whally, N.; Pandey, S.K.; Revill, M.; Rooney, C.; Buckett, L.K.; et al. Targeting KRAS-dependent tumors with AZD4785, a high-affinity therapeutic antisense oligonucleotide inhibitor of KRAS. Sci. Transl. Med. 2017, 9, eaal5253. [CrossRef]

117. Zeng, M.; Xiong, Y.; Safaee, N.; Nowal, R.P.; Donovan, K.A.; Yuan, C.J.; Gero, T.W.; Feru, F.; Li, L. Exploring Targeted Degradation Strategy for Oncogenic KRASG12C. Cell Chem. Biol. 2020, 27, 19-31. [CrossRef]

118. Bond, M.J.; Chu, L.; Nalawansha, D.A.; Li, K.; Crews, C. Targeted Degradation of Oncogenic KRASG12C by VHL-recruiting PROTACs. ChemRxiv 2020.

119. Merlet, J.; Burger, J.; Gomes, J.-E.; Pintard, L. Regulation of cullin-RING E3 ubiquitin-ligases by neddylation and dimerization. Cell. Mol. Life Sci. 2009, 66, 1924-1938. [CrossRef]

120. Engelman, J.A.; Chen, L.; Tan, X.; Crosby, K.; Guimaraes, A.R.; Upadhyay, R.; Maira, M.; McNamara, K.; Perera, S.A.; Song, Y.; et al. Effective use of PI3K and MEK inhibitors to treat mutant Kras G12D and PIK3CA H1047R murine lung cancers. Nat. Med. 2008, 14, 1351-1356. [CrossRef]

121. Tolcher, A.W.; Bendell, J.C.; Papadopoulus, K.P.; Burris, H.A., 3rd; Patnaik, A.; Jones, S.F.; Rasco, D.; Cox, D.S.; Durante, M.; Bellew, K.M.; et al. A phase IB trial of the oral MEK inhibitor trametinib (GSK1120212) in combination with everolimus in patients with advanced solid tumors. Ann. Oncol. 2015, 26, 58-64. [CrossRef] [PubMed]

122. Broutin, S.; Stewart, A.; Thavasu, P.; Paci, A.; Bidart, J.-M.; Banerji, U. Insights into significance of combined inhibition of MEK and m-TOR signalling output in KRAS mutant non-small-cell lung cancer. Br. J. Cancer 2016, 115, 549-552. [CrossRef] [PubMed]

123. Liang, S.-Q.; Bührer, E.D.; Berezowska, S.; Marti, T.M.; Xu, D.; Froment, L.; Yang, H.; Hall, S.R.R.; Vassella, E.; Yang, Z.; et al. mTOR mediates a mechanism of resistance to chemotherapy and defines a rational combination strategy to treat KRAS-mutant lung cancer. Oncogene 2019, 38, 622-636. [CrossRef] [PubMed]

124. Tolcher, A.W.; Khan, K.; Ong, M.; Banerji, U.; Papadimitrakopoulou, V.; Gandara, D.R.; Patnaik, A.; Baird, R.D.; Olmos, D.; Garrett, C.R.; et al. Antitumor activity in ras-driven tumors by blocking akt and mek. Clin. Cancer Res. 2015, 21, 739-748. [CrossRef] [PubMed]

125. Guerra, S.L.; Maertens, O.; Kuzmickas, R.; De Raedt, T.; Adeyemi, R.O.; Guild, C.J.; Guillemette, S.; Redig, A.J.; Chambers, E.S.; Xu, M.; et al. A Deregulated HOX Gene Axis Confers an Epigenetic Vulnerability in KRAS-Mutant Lung Cancers. Cancer Cell 2020, 37, 705-719. [CrossRef] [PubMed]

126. Manchado, E.; Weissmueller, S.; Morris, J.P., 4th; Chen, C.-C.; Wullenkord, R.; Lujambio, A.; De Stanchia, E.; Poirier, J.T.; Gainor, J.F.; Corcoran, R.B.; et al. A combinatorial strategy for treating KRAS-mutant lung cancer. Nature 2016, 534, 647-651. [CrossRef] 
127. Molina-Arcas, M.; Moore, C.; Rana, S.; Van Maldegem, F.; Mugarza, E.; Romero-Clavijo, P.; Herbert, E.; Horswell, S.; Li, L.-S.; Janes, M.R.; et al. Development of combination therapies to maximize the impact of KRAS-G12C inhibitors in lung cancer. Sci. Transl. Med. 2019, 11, eaaw7999. [CrossRef]

128. Chenard-Poirier, M.; Kaiser, M.; Boyd, K.; Sriskandarajah, P.; Constantinidou, A.; Harris, S.J.; Fandos, S.S.; Ryan, A.; Witt, K.; Dawes, J.C.; et al. Results from the biomarker-driven basket trial of RO5126766 (CH5127566), a potent RAF/MEK inhibitor, in RAS- or RAF-mutated malignancies including multiple myeloma. J. Clin. Oncol. 2017, 3515 SUPPL, 2506. [CrossRef]

129. Athuluri-Divakar, S.K.; Vasquez-Del Carpio, R.; Dutta, K.; Baker, S.J.; Cosenza, S.C.; Basu, I.; Gupta, Y.K.; Reddy, M.V.R.; Ueno, L.; Hart, J.R.; et al. A Small Molecule RAS-Mimetic Disrupts RAS Association with Effector Proteins to Block Signaling. Cell 2016, 165, 643-655. [CrossRef]

130. Citri, A.; Yarden, Y. EGF-ERBB signalling: towards the systems level. Nat. Rev. Mol. Cell Biol. 2006, 7, 505-516. [CrossRef]

131. Massarelli, E.; Varella-Garcia, M.; Tang, X.; Xavier, A.C.; Ozburn, N.C.; Liu, D.D.; Bekele, B.N.; Herbst, R.S.; Wistuba, I.I. KRAS Mutation Is an Important Predictor of Resistance to Therapy With Epidermal Growth Factor Receptor Tyrosine Kinase Inhibitors in Non-Small-Cell Lung Cancer. Clin. Cancer Res. 2007, 13, 2890-2896. [CrossRef] [PubMed]

132. Cadranel, J.; Mauguen, A.; Faller, M.; Zalcman, G.; Buisine, M.-P.; Westeel, V.; Longchampt, E.; Wislez, M.; Coudert, B.; Daniel, C.; et al. Impact of systematic EGFR and KRAS mutation evaluation on progression-free survival and overall survival in patients with advanced non-small-cell lung cancer treated by erlotinib in a French prospective cohort (ERMETIC project-part 2). J. Thorac. Oncol. 2012, 7, 1490-1502. [CrossRef] [PubMed]

133. Rulli, E.; Marabese, M.; Torri, V.; Farina, G.; Veronese, S.; Bettini, A.; Longo, F.; Moscetti, L.; Ganzinelli, M.; Lauricella, C.; et al. Value of KRAS as prognostic or predictive marker in NSCLC: results from the TAILOR trial. Ann. Oncol. 2015, 26, 2079-2084. [CrossRef] [PubMed]

134. Mao, C.; Qiu, L.-X.; Liao, R.-Y.; Du, F.-B.; Ding, H.; Yang, W.-C.; Li, J.; Chen, Q. KRAS mutations and resistance to EGFR-TKIs treatment in patients with non-small cell lung cancer: A meta-analysis of 22 studies. Lung Cancer 2010, 69, 272-278. [CrossRef] [PubMed]

135. Linardou, H.; Dahabreh, I.J.; Kanaloupiti, D.; Siannis, F.; Bafaloukos, D.; Kosmidis, P.; Papadimitriou, C.A.; Murray, S. Assessment of somatic k-RAS mutations as a mechanism associated with resistance to EGFR-targeted agents: a systematic review and meta-analysis of studies in advanced non-small-cell lung cancer and metastatic colorectal cancer. Lancet. Oncol. 2008, 9, 962-972. [CrossRef]

136. Molina-Arcas, M.; Hancock, D.C.; Sheridan, C.; Kumar, M.S.; Downward, J. Coordinate direct input of both KRAS and IGF1 receptor to activation of PI3 kinase in KRAS-mutant lung cancer. Cancer Discov. 2013, 3, 548-563. [CrossRef]

137. Navas, C.; Hernández-Porras, I.; Schuhmacher, A.J.; Sibilia, M.; Guerra, C.; Barbacid, M. EGF Receptor Signaling Is Essential for K-Ras Oncogene-Driven Pancreatic Ductal Adenocarcinoma. Cancer Cell 2012, 22, 318-330. [CrossRef]

138. Ardito, C.M.; Grüner, B.M.; Takeuchi, K.K.; Lubeseder-Martellato, C.; Teichmann, N.; Mazur, P.K.; Delgiorno, K.E.; Carpenter, E.S.; Halbrook, C.J.; Hall, J.C.; et al. EGF receptor is required for KRAS-induced pancreatic tumorigenesis. Cancer Cell 2012, 22, 304-317. [CrossRef]

139. Sun, C.; Hobor, S.; Bertotti, A.; Zecchin, D.; Huang, S.; Galimi, F.; Cottino, F.; Prahallad, A.; Grernrum, W.; Tzani, A.; et al. Intrinsic resistance to MEK inhibition in KRAS mutant lung and colon cancer through transcriptional induction of ERBB3. Cell Rep. 2014, 7, 86-93. [CrossRef]

140. Moll, H.P.; Pranz, K.; Musteanu, M.; Grabner, B.; Hruschka, N.; Mohrherr, J.; Aigner, P.; Stiedl, P.; Brcic, L.; Laszlo, V.; et al. Afatinib restrains K-RAS-driven lung tumorigenesis. Sci. Transl. Med. 2018, 10, eaao2301. [CrossRef]

141. Kruspig, B.; Monteverde, T.; Neidler, S.; Hock, A.; Kerr, E.; Nixon, C.; Clark, W.; Hedley, A.; Laing, S.; Coffelt, S.B.; et al. The ERBB network facilitates KRAS-driven lung tumorigenesis. Sci. Transl. Med. 2018, 10, eaao2565. [CrossRef] [PubMed]

142. Vander Heiden, M.G.; Cantley, L.C.; Thompson, C.B. Understanding the Warburg effect: the metabolic requirements of cell proliferation. Science 2009, 324, 1029-1033. [CrossRef] [PubMed] 
143. Hu, Y.; Lu, W.; Chen, G.; Wang, P.; Chen, Z.; Zhou, Y.; Ogasawara, M.; Trachootham, D.; Feng, L.; Pelicano, H.; et al. K-ras(G12V) transformation leads to mitochondrial dysfunction and a metabolic switch from oxidative phosphorylation to glycolysis. Cell Res. 2012, 22, 399-412. [CrossRef] [PubMed]

144. Hanahan, D.; Weinberg, R.A. Hallmarks of cancer: the next generation. Cell 2011, 144, 646-674. [CrossRef]

145. Kerr, E.M.; Martins, C.P. Metabolic rewiring in mutant Kras lung cancer. FEBS J. 2018, 285, 28-41. [CrossRef]

146. Pylayeva-Gupta, Y.; Grabocka, E.; Bar-Sagi, D. RAS oncogenes: weaving a tumorigenic web. Nat. Rev. Cancer 2011, 11, 761-774. [CrossRef]

147. Bryant, K.L.; Mancias, J.D.; Kimmelman, A.C.; Der, C.J. KRAS: feeding pancreatic cancer proliferation. Trends Biochem. Sci. 2014, 39, 91-100. [CrossRef]

148. Osugi, J.; Yamaura, T.; Muto, S.; Okabe, N.; Matsumura, Y.; Hoshino, M.; Higuchi, M.; Suzuki, H.; Gotoh, M. Prognostic impact of the combination of glucose transporter 1 and ATP citrate lyase in node-negative patients with non-small lung cancer. Lung Cancer 2015, 88, 310-318. [CrossRef]

149. Chen, G.; Gharib, T.G.; Wang, H.; Huang, C.-C.; Kucik, R.; Thomas, D.G.; Shedden, K.A.; Misek, D.E.; Taylor, J.M.G.; Giordano, T.; et al. Protein profiles associated with survival in lung adenocarcinoma. Proc. Natl. Acad. Sci. USA 2003, 100, 13537-13542. [CrossRef]

150. Lee, S.Y.; Jin, C.C.; Choi, J.E.; Hong, M.J.; Jung, D.K.; Do, S.K.; Baek, S.A.; Kang, H.J.; Kang, H.-G.; Choi, S.H.; et al. Genetic polymorphisms in glycolytic pathway are associated with the prognosis of patients with early stage non-small cell lung cancer. Sci. Rep. 2016, 6, 35603. [CrossRef]

151. Puzone, R.; Savarino, G.; Salvi, S.; Dal Bello, M.G.; Barletto, G.; Genova, C.; Rijavec, E.; Sini, C.; Esposito, A.I.; Ratto, G.B.; et al. Glyceraldehyde-3-phosphate dehydrogenase gene over expression correlates with poor prognosis in non small cell lung cancer patients. Mol. Cancer 2013, 12, 97. [CrossRef] [PubMed]

152. Wang, D.; Moothart, D.R.; Lowy, D.R.; Qian, X. The expression of glyceraldehyde-3-phosphate dehydrogenase associated cell cycle (GACC) genes correlates with cancer stage and poor survival in patients with solid tumors. PLoS One 2013, 8, e61262. [CrossRef] [PubMed]

153. Patra, K.C.; Wang, Q.; Bhaskar, P.T.; Miller, L.; Wang, Z.; Wheaton, W.; Chandel, N.; Laakso, M.; Muller, W.J.; Allen, E.L.; et al. Hexokinase 2 is required for tumor initiation and maintenance and its systemic deletion is therapeutic in mouse models of cancer. Cancer Cell 2013, 24, 213-228. [CrossRef] [PubMed]

154. Guo, W.; Zhang, Y.; Chen, T.; Wang, Y.; Xue, J.; Zhang, Y.; X, W.; Mo, X.; Lu, Y. Efficacy of RNAi targeting of pyruvate kinase M2 combined with cisplatin in a lung cancer model. J. Cancer Res. Clin. Oncol. 2011, 137, 65-72. [CrossRef] [PubMed]

155. Shi, H.; Li, D.; Zhang, J.; Wang, Y.-S.; Yang, L.; Zhang, H.-L.; Wang, X.-H.; Mu, B.; Wang, W.; Ma, Y.; et al. Silencing of pkm2 increases the efficacy of docetaxel in human lung cancer xenografts in mice. Cancer Sci. 2010, 101, 1447-1453. [CrossRef]

156. Xie, H.; Hanai, J.-I.; Ren, J.-G.; Kats, L.; Burgess, K.; Bhargava, P.; Signoretti, S.; Billiard, J.; Duffy, K.J.; Grant, A.; et al. Targeting lactate dehydrogenase-A inhibits tumorigenesis and tumor progression in mouse models of lung cancer and impacts tumor-initiating cells. Cell Metab. 2014, 19, 795-809. [CrossRef]

157. Altman, J.K.; Szilard, A.; Goussetis, D.J.; Sassano, A.; Colamonici, M.; Gounaris, W.; Frankfurt, O.; Giles, F.J.; Eklund, E.A.; Beauchamp, E.M.; et al. Autophagy is a survival mechanism of acute myelogenous leukemia precursors during dual mTORC2/mTORC1 targeting. Clin. Cancer Res. 2014, 20, 2400-2409. [CrossRef]

158. Zhuang, K.; Guo, H.; Tang, H.; Yuan, Y.; Jun, Z.; Lingxia, Z.; Kun, H.; Xin, Z. Gastrin enhances autophagy and promotes gastric carcinoma proliferation via inducing AMPK $\alpha$. Oncol. Res. 2017, 25, 1399-1407.

159. Masui, A.; Hamada, M.; Kameyama, H.; Wakabayashi, K.; Takasu, A.; Imai, T.; Iwai, S.; Yura, Y. Autophagy as a survival mechanism for squamous cell carcinoma cells in endonuclease g-mediated apoptosis. PLoS One 2016, 11, e0162786. [CrossRef]

160. Tan, Q.; Wang, M.; Yu, M.; Zhang, J.; Bristow, R.G.; Hill, R.P.; Tannock, I.F. Role of Autophagy as a Survival Mechanism for Hypoxic Cells in Tumors. Neoplasia 2016, 18, 347-355. [CrossRef]

161. Fitzwalter, B.E.; Thorburn, A. Recent insights into cell death and autophagy. FEBS J. 2015, 282, 4279-4288. [CrossRef] [PubMed]

162. Guo, J.Y.; Chen, H.Y.; Mathew, R.; Fan, J.; Strohecker, A.M.; Karsli-Uzunbas, G.; Kamphorst, J.J.; Chen, G.; Lemons, J.M.S.; Karantza, V.; et al. Activated Ras requires autophagy to maintain oxidative metabolism and tumorigenesis. Genes Dev. 2011, 25, 460-470. [CrossRef] [PubMed] 
163. Yang, S.; Wang, X.; Contino, G.; Liesa, M.; Sahin, E.; Ying, H.; Bause, A.; Li, Y.; Stommel, J.M.; Dell'antonio, G.; et al. Pancreatic cancers require autophagy for tumor growth. Genes Dev. 2011, 25, 717-729. [CrossRef] [PubMed]

164. Eng, C.H.; Wang, Z.; Tkac, H.D.; Toral-Barza, L.; Ugwonali, S.; Liu, S.; Fitzgerald, S.L.; George, E.; Frias, E.; Cochran, N.; et al. Macroautophagy is dispensable for growth of KRAS mutant tumors and chloroquine efficacy. Proc. Natl. Acad. Sci. USA 2016, 113, 182-187. [CrossRef]

165. Bryant, K.L.; Stalnecker, C.A.; Zeitouni, D.; Klomp, J.E.; Peng, S.; Tikunov, A.P.; Gunda, V.; Pierobon, M.; Waters, A.M.; George, S.D.; et al. Combination of ERK and autophagy inhibition as a treatment approach for pancreatic cancer. Nat. Med. 2019, 25, 628-640. [CrossRef]

166. Kinsey, C.G.; Camolotto, S.A.; Boespflug, A.M.; Guillen, K.P.; Foth, M.; Truong, A.; Schuman, S.S.; Shea, J.E.; Seipp, M.T.; Yap, J.T.; et al. Protective autophagy elicited by $\mathrm{RAF} \rightarrow \mathrm{MEK} \rightarrow \mathrm{ERK}$ inhibition suggests a treatment strategy for RAS-driven cancers. Nat. Med. 2019, 25, 620-627. [CrossRef]

167. Lee, C.-S.; Lee, L.C.; Yuan, T.L.; Chakka, S.; Fellmann, C.; Lowe, S.W.; Caplen, N.J.; McCormick, F.; Luo, J. MAP kinase and autophagy pathways cooperate to maintain RAS mutant cancer cell survival. Proc. Natl. Acad. Sci. USA 2019, 116, 4508-4517. [CrossRef]

168. Guo, J.Y.; Karsli-Uzunbas, G.; Mathew, R.; Aisner, S.C.; Kamphorst, J.J.; Strohecker, A.M.; Chen, G.; Price, S.; Lu, W.; Teng, X.; et al. Autophagy suppresses progression of K-ras-induced lung tumors to oncocytomas and maintains lipid homeostasis. Genes Dev. 2013, 27, 1447-1461. [CrossRef]

169. Weinberg, F.; Hamanaka, R.; Wheaton, W.W.; Weinberg, S.; Joseph, J.; Lopez, M.; Kalyanaraman, B.; Mutlu, G.M.; Budinger, G.R.S.; Chandel, N.S. Mitochondrial metabolism and ROS generation are essential for Kras-mediated tumorigenicity. Proc. Natl. Acad. Sci. USA 2010, 107, 8788-8793. [CrossRef]

170. Shackelford, D.B.; Abt, E.; Gerken, L.; Vasquez, D.S.; Seki, A.; Leblanc, M.; Wei, L.; Fishbein, M.C.; Czernin, J.; Mischel, P.S.; et al. LKB1 Inactivation Dictates Therapeutic Response of Non-Small Cell Lung Cancer to the Metabolism Drug Phenformin. Cancer Cell 2013, 23, 143-158. [CrossRef]

171. Ho, P.-C.; Liu, P.-S. Metabolic communication in tumors: A new layer of immunoregulation for immune evasion. J. Immunother. Cancer 2016, 4, 4. [CrossRef] [PubMed]

172. Fischer, K.; Hoffmann, P.; Voelkl, S.; Meidenbauer, N.; Ammer, J.; Edinger, M.; Gottfriend, E.; Schwarz, S.; Rother, G.; Hoves, S.; et al. Inhibitory effect of tumor cell-derived lactic acid on human T cells. Blood 2007, 109, 3812-3819. [CrossRef] [PubMed]

173. Pollizzi, K.N.; Sun, I.-H.; Patel, C.H.; Lo, Y.-C.; Oh, M.-H.; Waickman, A.T.; Tam, A.J.; Blosser, R.L.; Wen, J.; Delgoffe, G.M.; et al. Asymmetric inheritance of mTORC1 kinase activity during division dictates CD8+ T cell differentiation. Nat. Immunol. 2016, 17, 704-711. [CrossRef] [PubMed]

174. Martinez-Outschoorn, U.E.; Pavlides, S.; Howell, A.; Pestell, R.G.; Tanowitz, H.B.; Sotgia, F.; Lisanti, M.P. Stromal-epithelial metabolic coupling in cancer: Integrating autophagy and metabolism in the tumor microenvironment. Int. J. Biochem. Cell Biol. 2011, 43, 1045-1051. [CrossRef]

175. Borghaei, H.; Paz-Ares, L.; Horn, L.; Spigel, D.R.; Steins, M.; Ready, N.E.; Chow, L.Q.; Vokes, E.E.; Felip, E.; Holgado, E.; et al. Nivolumab versus docetaxel in advanced nonsquamous non-small-cell lung cancer. N. Engl. J. Med. 2015, 373, 1627-1639. [CrossRef]

176. Brahmer, J.; Reckamp, K.L.; Baas, P.; Crinò, L.; Eberhardt, W.E.E.; Poddubskaya, E.; Antonia, S.; Pluzanski, A.; Vokes, E.E.; Holgado, E.; et al. Nivolumab versus docetaxel in advanced squamous-cell non-small-cell lung cancer. N. Engl. J. Med. 2015, 373, 123-135. [CrossRef]

177. Rittmeyer, A.; Barlesi, F.; Waterkamp, D.; Park, K.; Ciardiello, F.; Von Pawel, J.; Gadgeel, S.M.; Hida, T.; Kowalski, D.M.; Dols, M.C.; et al. Atezolizumab versus docetaxel in patients with previously treated non-small-cell lung cancer (OAK): a phase 3, open-label, multicentre randomised controlled trial. Lancet. 2017, 389, 255-265. [CrossRef]

178. Herbst, R.S.; Baas, P.; Kim, D.-W.; Felip, E.; Pérez-Garcia, J.L.; Han, J.-Y.; Molina, J.; Kim, J.-H.; Arvis, C.D.; Ahn, M.-J.; et al. Pembrolizumab versus docetaxel for previously treated, PD-L1-positive, advanced non-small-cell lung cancer (KEYNOTE-010): A randomised controlled trial. Lancet 2016, 387, 1540-1550. [CrossRef]

179. Reck, M.; Rodríguez-Abreu, D.; Robinson, A.G.; Hui, R.; Csőszi, T.; Fülöp, A.; Gottfried, M.; Peled, N.; Tafreshi, A.; Cuffe, S.; et al. Pembrolizumab versus Chemotherapy for PD-L1-Positive Non-Small-Cell Lung Cancer. N. Engl. J. Med. 2016, 375, 1823-1833. [CrossRef] 
180. Zugazagoitia, J.; Molina-Pinel, S.; Lopez-Rios, F.; Paz-Ares, L. Biological therapies in nonsmall cell lung cancer. Eur. Respir. J. 2017, 49, 1601520. [CrossRef]

181. Adderley, H.; Blackhall, F.H.; Lindsay, C.R. KRAS-mutant non-small cell lung cancer: Converging small molecules and immune checkpoint inhibition. EBioMedicine 2019, 41, 711-716. [CrossRef] [PubMed]

182. Lee, C.K.; Man, J.; Lord, S.; Cooper, W.; Links, M.; Gebski, V.; Herbst, R.S.; Gralla, R.J.; Mok, T.; Yang, J.C.-H. Clinical and molecular characteristics associated with survival among patients treated with checkpoint inhibitors for advanced non-small cell lung carcinoma: A systematic review and meta-analysis. JAMA Oncol. 2018, 4, 210-216. [CrossRef] [PubMed]

183. Schoenfeld, A.J.; Rizvi, H.; Bandlamudi, C.; Sauter, J.L.; Travis, W.D.; Rekhtman, N.; Plodkowski, A.J.; Perez-Johnston, R.; Sawan, P.; Beras, A.; et al. Clinical and molecular correlates of PD-L1 expression in patients with lung adenocarcinomas. Ann. Oncol. 2020, 31, 599-608. [CrossRef]

184. Gianoncelli, L.; Spitaleri, G.; Passaro, A.; Radice, D.; Fumagalli, C.; Del Signore, W.; Sati, V.; Catania, C.M.; Guerini-Rocco, E.; Barberis, M.; et al. Efficacy of Anti-PD1/PD-L1 Therapy (IO) in KRAS Mutant Non-small Cell Lung Cancer Patients: A Retrospective Analysis. Anticancer Res. 2020, 40, 427-433. [CrossRef] [PubMed]

185. Kauffmann-Guerrero, D.; Tufman, A.; Kahnert, K.; Bollmann, B.A.; Reu, S.; Syunyaeva, Z.; Schneider, C.; Manapov, F.; Huber, R.M.; Golpon, H. Response to Checkpoint Inhibition in Non-Small Cell Lung Cancer with Molecular Driver Alterations. Oncol. Res. Treat. 2020, 43, 289-298. [CrossRef] [PubMed]

186. Skoulidis, F.; Heymach, J.V. Co-occurring genomic alterations in non-small-cell lung cancer biology and therapy. Nat. Rev. Cancer 2019, 19, 495-509. [CrossRef] [PubMed]

187. Skoulidis, F.; Goldberg, M.E.; Greenawalt, D.M.; Hellmann, M.D.; Awad, M.M.; Gainor, J.F.; Schrock, A.B.; Hartmaier, R.J.; Trabucco, S.E. STK11/LKB1 Mutations and PD-1 Inhibitor Resistance in KRAS-Mutant Lung Adenocarcinoma. Cancer Discov. 2018, 8, 822-835. [CrossRef]

188. Hellmann, M.D.; Nathanson, T.; Rizvi, H.; Creelan, B.C.; Sanchez-Vega, F.; Ahuja, A.; Ni, A.; Novik, J.B.; Mangarin, L.M.B.; Abu-Akeel, M.; et al. Genomic Features of Response to Combination Immunotherapy in Patients with Advanced Non-Small-Cell Lung Cancer. Cancer Cell 2018, 33, 843-852. [CrossRef]

189. Koyama, S.; Akbay, E.A.; Li, Y.Y.; Aref, A.R.; Skoulidis, F.; Herter-Sprie, G.S.; Buczkowski, K.A.; Liu, Y.; Awad, M.M.; Denning, W.L.; et al. STK11/LKB1 deficiency promotes neutrophil recruitment and proinflammatory cytokine production to suppress T-cell activity in the lung tumor microenvironment. Cancer Res. 2016, 76, 999-1008. [CrossRef]

190. Arbour, K.C.; Jordan, E.; Kim, H.R.; Dienstag, J.; Yu, H.A.; Sanchez-Vega, F.; Lito, P.; Berger, M.; Solit, D.B.; Hellmann, M.; et al. Effects of co-occurring genomic alterations on outcomes in patients with KRAS-mutant non-small cell lung cancer. Clin. Cancer Res. 2018, 24, 334-340. [CrossRef]

191. Dong, Z.-Y.; Zhong, W.-Z.; Zhang, X.-C.; Su, J.; Xie, Z.; Liu, S.-Y.; Tu, H.-Y.; Chen, H.-J.; Sun, Y.-L.; Zhou, Q.; et al. Potential predictive value of TP53 and KRAS mutation status for response to PD-1 blockade immunotherapy in lung adenocarcinoma. Clin. Cancer Res. 2017, 23, 3012-3024. [CrossRef] [PubMed]

192. Neuwelt, A.J.; Kimball, A.K.; Johnson, A.M.; Arnold, B.W.; Bullock, B.L.; Kaspar, R.E.; Kleczko, E.K.; Kwak, J.W.; Wu, M.-H.; Heasley, L.E.; et al. Cancer cell-intrinsic expression of MHC II in lung cancer cell lines is actively restricted by MEK/ERK signaling and epigenetic mechanisms. J. Immunother. Cancer 2020, 8, e000441. [CrossRef] [PubMed]

193. Choi, H.; Deng, J.; Li, S.; Sali, T.; Dong, L.; Brea, E.J.; Houghton, S.; Redmond, D.; Zhong, H.; Boiarsky, J.; et al. Pulsatile MEK Inhibition Improves Anti-tumor Immunity and T Cell Function in Murine Kras Mutant Lung Cancer. Cell Rep. 2019, 27, 806-819.e5. [CrossRef] [PubMed]

194. Tran, E.; Robbins, P.F.; Lu, Y.-C.; Prickett, T.D.; Gartner, J.J.; Jia, L.; Pasetto, A.; Zheng, Z.; Ray, S.; Groh, E.M.; et al. T-cell transfer therapy targeting mutant KRAS in cancer. N. Engl. J. Med. 2016, 375, 2255-2262. [CrossRef]

(C) 2020 by the authors. Licensee MDPI, Basel, Switzerland. This article is an open access article distributed under the terms and conditions of the Creative Commons Attribution (CC BY) license (http://creativecommons.org/licenses/by/4.0/). 